\title{
Citizen science and sustainability transitions
}

\author{
Henry Sauermann ${ }^{\mathrm{a}, \mathrm{b}, *}$, Katrin Vohland ${ }^{\mathrm{c}}$, Vyron Antoniou ${ }^{\mathrm{d}}$, Bálint Balázs ${ }^{\mathrm{e}}$, Claudia Göbel ${ }^{\mathrm{c}, \mathrm{f}}$, \\ Kostas Karatzas $^{g}$, Peter Mooney ${ }^{\mathrm{h}}$, Josep Perello ${ }^{\mathrm{i}, \mathrm{j}}$, Marisa Ponti ${ }^{\mathrm{k}}$, Roeland Samson ${ }^{\mathrm{l}}$, Silvia Winter ${ }^{\mathrm{m}}$ \\ ${ }^{a}$ European School of Management and Technology (ESMT), Berlin, Schlossplatz 1, Berlin 10178, Germany \\ ${ }^{\mathrm{b}}$ National Bureau of Economic Research (NBER), 1050 Massachusetts Ave., Cambridge, MA 02138, United States \\ ${ }^{\mathrm{c}}$ Museum für Naturkunde Berlin (MfN), Leibniz Institute for Evolution and Biodiversity Science, Berlin, Invalidenstraße 43, Berlin 10115, Germany \\ ${ }^{\mathrm{d}}$ Hellenic Military Geographic Directorate, H.A.G.S. Papagou Headquarter Facilities, Mesogeion Ave. 227-231, Holargos 15669, Greece \\ ${ }^{\mathrm{e}}$ Environmental Social Science Research Group (ESSRG), Impact Hub Budapest, Ferenciek tere 2., Budapest 1053, Hungary \\ ${ }^{\mathrm{f}}$ Institute for Higher Education Research Halle-Wittenberg (HoF), Wittenberg, Collegienstraße 62, Lutherstadt Wittenberg 06886, Germany \\ ${ }^{\mathrm{g}}$ Environmental Informatics Research Group, School of Mechanical Engineering, Faculty of Engineering, Aristotle University of Thessaloniki, Egnatia Str., Box 483, \\ Thessaloniki 54124, Greece \\ ${ }^{\mathrm{h}}$ Geotechnologies Research Group, Department of Computer Science, Maynooth University, W23 F2H6 Maynooth, Co. Kildare, Ireland \\ ${ }^{\mathrm{i}}$ OpenSystems Research Group, Departament de Física de la Matèria Condensada, Universitat de Barcelona, Martí $i$ Franquès 1, Barcelona 08028, Spain \\ ${ }^{\mathrm{j}}$ Universitat de Barcelona Institute of Complex Systems, Martí $i$ Franquès 1, Barcelona 08028, Spain \\ ${ }^{\mathrm{k}}$ Department of Applied IT, University of Gothenburg, Forskningsgången 6, Göteborg 41756, Sweden \\ ${ }^{1}$ Lab of Environmental and Urban Ecology (EUREC-Air), University of Antwerp, Groenenborgerlaan 171, Antwerp 2020, Belgium \\ ${ }^{\mathrm{m}}$ University of Natural Resources and Life Sciences, Vienna (BOKU), Gregor-Mendel-Str. 33, Vienna 1180, Austria
}

\section{A R T I C L E I N F O}

\section{Keywords:}

Citizen science

Crowd science

Co-design

Sustainability transitions

Science and innovation studies

Science education

\begin{abstract}
A B S T R A C T
Citizen Science (CS) projects involve members of the general public as active participants in research. While some advocates hope that CS can increase scientific knowledge production ("productivity view"), others emphasize that it may bridge a perceived gap between science and the broader society ("democratization view"). We discuss how an integration of both views can allow Citizen Science to support complex sustainability transitions in areas such as renewable energy, public health, or environmental conservation. We first identify three pathways through which such impacts can occur: (1) Problem identification and agenda setting; (2) Resource mobilization; and (3) Facilitating socio-technical co-evolution. To realize this potential, however, CS needs to address important challenges that emerge especially in the context of sustainability transitions: Increasing the diversity, level, and intensity of participation; addressing the social as well as technical nature of sustainability problems; and reducing tensions between CS and the traditional institution of academic science. Grounded in a review of academic literature and policy reports as well as a broad range of case examples, this article contributes to scholarship on science, innovation, and sustainability transitions. We also offer insights for actors involved in initiating or institutionalizing Citizen Science efforts, including project organizers, funding agencies, and policy makers.
\end{abstract}

\section{Introduction}

Scholars pay increasing attention to Citizen Science (CS), the direct involvement of the public in scientific research. Studies of CS appear in a broad range of fields and outlets, revealing different views of opportunities and challenges (e.g., Bonney et al., 2014; Franzoni and Sauermann, 2014; Khatib et al., 2011; Wiggins and Crowston, 2011). While some see CS primarily as a means to increase the productivity of traditional scientific research, others see it as an opportunity to democratize science by opening traditional institutions (Irwin, 1995;
Nielsen, 2011). In this paper, we argue that these two views reflect complementary aspects of Citizen Science that give it the potential to help address sustainability problems, i.e., complex challenges to meet the needs of the present without jeopardizing the needs of future generations (United Nations, 1987). Such sustainability problems may relate to aspects of the natural environment such as preserving biodiversity or conserving natural resources, but also to socioeconomic issues such as health, poverty reduction, and other aspects of welfare and peace. The severity and the scope of today's sustainability problems are evident in the seventeen UN Sustainable Development Goals (SDGs; Fig. 1).

\footnotetext{
* Corresponding author.

E-mail address: henry.sauermann@esmt.org (H. Sauermann).
} 

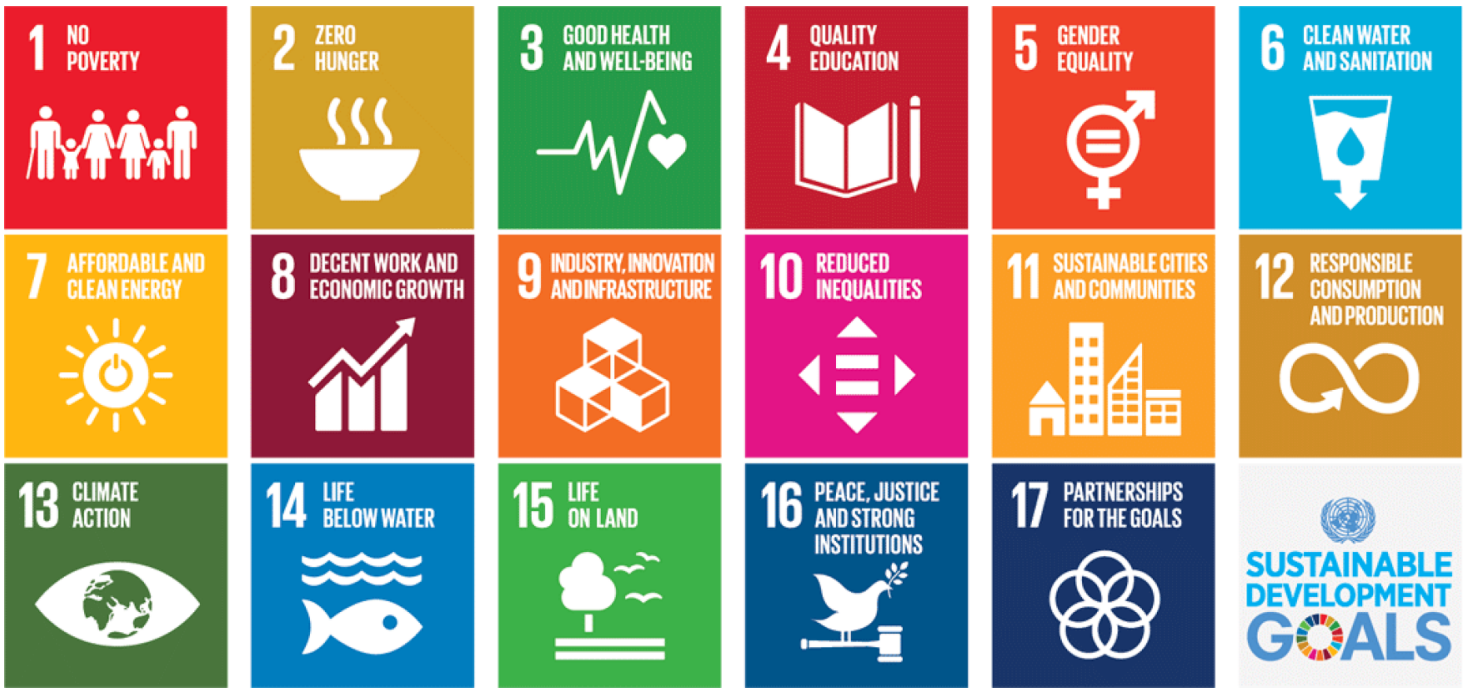

Fig. 1. United Nations Sustainable Development Goals (SDGs). Source: https://www.un.org/sustainabledevelopment/sustainable-development-goals/.

To discuss how Citizen Science can help address sustainability problems, we integrate two streams of literature. The first includes research on Citizen Science that discusses how the general public can get involved in all stages of the research process (Bonney et al., 2009; Irwin, 1995; West and Pateman, 2017). This work demonstrates that citizens can increase the production of valuable scientific knowledge by contributing significant effort and knowledge resources to projects. At the same time, CS can allow citizens to shape the direction of research, learn, and advocate more effectively for socio-political changes.

The second stream encompasses work on sustainability transitions (STs) - transformation processes through which socio-technical systems shift to more sustainable modes of production and consumption (Hölscher et al., 2018; Markard et al., 2012; Smith et al., 2005). This literature informs us that STs are often enabled by new scientific knowledge and technologies in areas such as renewable energy, efficient transportation systems, sustainable agricultural methods, or vaccines and public sanitation (Geels, 2006; Jury and Vaux, 2005; Mowery et al., 2010). However, technological innovation needs to coevolve with social and institutional structures. Attention to this sociotechnical intermingling is required both to understand sustainability transitions and to manage them (Geels and Schot, 2007; Markard et al., 2012; Smith et al., 2010).

Drawing on both literatures, we argue that Citizen Science can support sustainability transitions through three important pathways: (1) Helping identify sustainability problems and setting research agendas; (2) Mobilizing resources in the form of effort and knowledge; and (3) Facilitating the co-evolution of socio-technical aspects of transitions. Notwithstanding this considerable potential, we also identify important challenges for Citizen Science that emerge especially in the context of STs: (1) Increasing the diversity, levels, and intensity of participation; (2) Addressing technical as well as social aspects of sustainability problems; and (3) Reducing tensions with the traditional institution of academic science. We discuss these challenges, clarify how they affect each of the three pathways connecting CS and STs, and assess the evidence regarding potential solutions.

Our discussion builds on the scholarly literatures on CS and STs, related policy documents, as well as published case studies of CS projects. We also synthesize discussions at several International Citizen Science Conferences ${ }^{1}$ as well as a workshop of the EU COST Action "Citizen Science to promote creativity, scientific literacy, and

\footnotetext{
${ }^{1} 2015$ San Jose, USA; 2016 Berlin, Germany; 2017 St. Paul, USA; 2018 Geneva, Switzerland; 2019 Raleigh, USA.
}

innovation throughout Europe". ${ }^{2}$ In that workshop, participants identified key opportunities and challenges for Citizen Science in an iterative way by clustering insights derived from brainstorming and visual mapping. Co-authors also contributed to this article insights from their experiences as initiators of CS projects, several of which included participant surveys and feedback meetings with citizens and other stakeholders. $^{3}$ In addition, we had discussions with leaders of large CS platforms such as Zooniverse.org, Experiment.com, and Scienceathome.org to learn about their experiences and ask about topics such as participation challenges, project outcomes, and the relations between professional and citizen scientists. Finally, we gained insights through interactions with citizens outside of particular CS projects. For example, one co-author mentored high school students who developed a framework to engage young citizens using CS approaches. ${ }^{4}$ Other co-authors interacted with citizens in their capacity as leaders of public engagement with science efforts at a Natural History Museum. To learn about the perspectives of citizens who have not yet participated in CS, we also gathered input through a survey on the MTurk platform. ${ }^{5}$

Citizen Science has raised great hopes among scientists, civil society groups, and policy makers. For example, the European Citizen Science Association's (2015) strategy sets an explicit goal to contribute to sustainability transformation, the European Commission (2017) recommends to mobilize citizens for research in order to enhance the impact of EU research and innovation programs, and the U.S. Federal Citizen Science Initiative (2018) also seeks to foster citizens' involvement in research. Although some of the prior literature takes a strong normative stand (Felt and Fochler, 2008), our goal is to develop a systematic and balanced understanding of the opportunities and challenges of Citizen Science in the particular context of

\footnotetext{
${ }^{2}$ https://cs-eu.net/wgs

${ }^{3}$ Examples of projects include https://airbezen.be/, http://www.urwatair.gr/, https://app.inspiresproject.com/projects/6-fix-my-food-system, http://igelimgarten.boku.ac.at, http://www.togetherscience.eu/, http:// www.ub.edu/opensystems/projectes/, and https://www.sparklingscience.at/ en.

${ }^{4}$ https://www.young-economic-summit.org/en/involving-citizens-in-research-improving-science-and-society-2/

${ }^{5}$ This survey on the MTurk crowdsourcing platform was the pilot for a broader study of participation patterns and project choices in CS. For the current paper, we draw on open ended responses from over 100 citizens who had not yet participated in CS to illustrate their perceptions of opportunities and barriers for personal participation. Quantitative data from the main survey will be presented elsewhere.
} 
sustainability transitions.

\section{Background: the citizen science landscape}

Non-professionals ("citizens") have been doing research for centuries (Mahr, 2014; Shapin, 2008; Strasser, 2012). In this sense, Citizen Science pre-dates institutionalized research. One of the oldest ongoing projects framed as CS is the Audubon Society's Christmas Bird Count, started in 1900 (Miller-Rushing et al., 2012). This project has been followed by many others that typically involved local communities in monitoring and data collection activities. New technologies such as mobile phones and the internet give citizens an increasing set of tools to help with research and allow them to participate in physical as well as virtual space (Newman et al., 2012). As such, there has been a dramatic rise in the number and diversity of CS projects in the last decade. ${ }^{6}$

Citizen Science projects are now active in a wide range of fields such as biological conservation, astronomy, medicine, environmental science, and archeology. A common typology distinguishes projects based on the extent of citizens' involvement in the research process (Bonney et al., 2009; Follett and Strezov, 2015). First, citizens may help professional scientists by participating in a narrow range of activities, typically collecting or processing data ("contributory projects"). For example, participants in the global project eBird record bird sightings, contributing data for professional researchers who study the impact of environmental and human influences on animal populations (Sullivan et al., 2009). Second, citizens can participate in a broader range of activities, including aspects such as developing data collection methods or analyzing data, although the goals of the project are still defined by professional project leaders ("collaborative projects"). Third, citizens can be involved in the full set of activities, notably including the formulation of research questions that will be addressed in the project ("co-created projects"). Finally, while co-created projects still involve professional scientists, citizens can also perform all aspects of the research without professionals (what we call "autonomous" Citizen Science). Surveys of the CS landscape show that most current projects are contributory in nature (Franzoni and Sauermann, 2014; Hecker et al., 2018; Science Europe, 2018; Turrini et al., 2018). ${ }^{7}$

Before considering how Citizen Science can support sustainability transitions, it is useful to clarify its key features. Towards this end, we reviewed literature in different disciplines, including primary research using Citizen Science approaches as well as scholarly discussions of CS and related policy reports. We also synthesized discussions with professional scientists and citizens engaged in CS. Finally, we abstracted from nuances to identify six broader dimensions that capture the overarching rationale for involving citizens in research, underlying assumptions, key mechanisms that are used, as well as implications for the institution of science. In this process, we realized that convergence on a single characterization of Citizen Science along these dimensions was impossible: Instead, two quite different views emerged.

Table 1 summarizes these two views. We note that these are "idealtypes", i.e., abstract models that emphasize central features and facilitate comparative analysis (Sauermann and Stephan, 2013; Weber, 1997). Our claim is not that all scholars fully endorse one of these views, nor that all projects fit neatly in one or the other. However, outlining these two views provides a useful basis to discuss how core aspects of Citizen Science can support socio-technical sustainability transitions. More importantly, clarifying differences in the goals, underlying assumptions, and mechanisms of the two views points towards

\footnotetext{
${ }^{6}$ Catalogs of projects include https://scistarter.com/ and http://www. buergerschaffenwissen.de/.

${ }^{7}$ Although discussions of Citizen Science typically focus on contributions of time and knowledge, citizens have also started to provide financial resources by crowdfunding research projects. This includes a large share of projects addressing sustainability problems (Sauermann et al., 2019).
}

important challenges that Citizen Science is facing, especially in the context of STs. ${ }^{8}$

First, a "productivity view" is rooted in the traditional professional scientific enterprise. The main rationale for involving citizens in research is that professional scientists can obtain additional resources for research and accelerate the production of scientific knowledge (Christian et al., 2012; Khatib et al., 2011; Nielsen, 2011). This view adopts the premise that scientific knowledge is intrinsically valuable and will - at least in the long-term - be beneficial for society (Bush, 1945; Simis et al., 2016; Woolley et al., 2016). Projects are led by professional scientists, and citizens contribute through activities such as collecting large amounts of data, performing labeling and analysis tasks, or creative problem solving. The benefits of citizens' involvement can be measured in terms of hours worked, the volume of data processed, or the number of publications written based on CS data (Burgess et al., 2017; Follett and Strezov, 2015; Sauermann and Franzoni, 2015). In this view, Citizen Science does not question the supremacy of professional expertise and does not challenge the norms and performance standards of professional science; science remains a distinct institutional sphere. Central aspects of this productivity view are reflected in many of the case reports written by professional scientists as well as analyses by economists and management scholars (e.g., Bonney et al., 2009; Christian et al., 2012; Khatib et al., 2011; Sauermann and Franzoni, 2015).

Second, a "democratization view" sees Citizen Science as the contextualization of research in society and challenges the separation of science from society. An important premise is that the value of knowledge depends on the needs and preferences of the broader public, and that attention is needed to unintended consequences of technoscientific progress along with the unequal distribution of its costs and benefits (Stilgoe et al., 2013). CS allows citizens to shape the direction of research towards societal needs and to contribute knowledge that may be underappreciated by the scientific establishment (Irwin 1995). CS increases the transparency of science and enables citizens to learn about particular objects of research (e.g., birds or air quality) as well as about the research process. This increases awareness of problems and enables citizens to advocate for socio-political changes (Hecker et al., 2018; Stilgoe, 2009). Projects are initiated and led by citizens; data and outputs are freely accessible (Groom et al., 2017). Although the aspiration is to do "science", the processes and standards of professional science are considered socially determined and contestable (McCormick, 2007; Ottinger, 2010). Similarly, the primacy of professional expertise and formal education can be challenged. Central aspects of this democratization view are salient in many projects initiated by citizens as well as in analyses by scholars in areas such as science and technology studies or public understanding of science (e.g., Haklay, 2015; Irwin, 1995; Ottinger, 2010).

In the following Section 3, we discuss how processes and outcomes highlighted by both views are necessary for Citizen Science to support sustainability transitions. However, integrating the two views also creates challenges, especially in the context of socio-technical transitions. We discuss key challenges and potential solutions in Section 4.

\section{Citizen science to support sustainability transitions}

Sustainability transitions can focus on many different aspects of nature and society (see Fig. 1). However, transitions are invariably of a socio-technical in nature, i.e., they involve new knowledge and

\footnotetext{
${ }^{8}$ Some articles draw a similar distinction between the "Bonney" vs. "Irwin" tradition of Citizen Science, referring to two seminal early contributors (Bonney et al., 2009; Irwin, 1995; Riesch and Potter, 2014; Woolley et al., 2016). Bonney and Irwin have continued to develop their perspectives on Citizen Science over the years; our two ideal-type views are on purpose more distinct to reduce overlap and highlight potential tensions.
} 
Table 1

Productivity vs. democratization view of Citizen Science (ideal-types).

\begin{tabular}{|c|c|c|}
\hline & Productivity View & Democratization View \\
\hline $\begin{array}{l}\text { Primary rationale for Citizen } \\
\text { Science }\end{array}$ & $\begin{array}{l}\text { Involving citizens increases professional scientists' research } \\
\text { productivity by mobilizing additional resources (e.g., effort } \\
\text { and knowledge inputs). }\end{array}$ & $\begin{array}{l}\text { CS democratizes science by allowing citizens to direct research towards } \\
\text { societally relevant problems. Citizens can take agency in the research process } \\
\text { as well as in the use of results. }\end{array}$ \\
\hline Epistemological premise & Scientific knowledge has intrinsic value. & $\begin{array}{l}\text { Scientific knowledge can generate benefits and risks, or be irrelevant. Its } \\
\text { value depends on the needs and preferences of the broader public. }\end{array}$ \\
\hline Extent of citizen involvement & $\begin{array}{l}\text { Selected stages of the research process (contributory and } \\
\text { collaborative CS). }\end{array}$ & $\begin{array}{l}\text { All stages of the research process, including problem definition (co-created } \\
\text { and autonomous CS). }\end{array}$ \\
\hline $\begin{array}{l}\text { Control of decisions and } \\
\text { ownership of outputs }\end{array}$ & Professional scientists. & Citizens. \\
\hline Key performance metrics & $\begin{array}{l}\text { Hours contributed, volume of data collected, number of } \\
\text { papers published. }\end{array}$ & $\begin{array}{l}\text { Number of citizens involved, societal problems solved, extent of social } \\
\text { change, citizen learning. }\end{array}$ \\
\hline Institutional implications & $\begin{array}{l}\text { Science is performed in the traditional system. CS accepts } \\
\text { professional expertise, norms and standards. }\end{array}$ & $\begin{array}{l}\text { CS extends the conduct of science beyond the traditional system. Challenges } \\
\text { professional expertise, norms and standards. }\end{array}$ \\
\hline
\end{tabular}

technologies as well as changes in behaviors and policies (Hölscher et al., 2018; Markard et al., 2012). Examples include transitions towards renewable energy sources, sustainable agricultural methods, or public sanitation.

A large literature examines how sustainability transitions unfold (for reviews, see Loorbach et al., 2017; Markard et al., 2012). We draw on this literature to highlight central features of STs and discuss how Citizen Science can support transitions via three pathways. Of course, our discussion is not meant to discuss all important aspects of sustainability transitions; rather, our goal is to identify areas where CS and STs can most fruitfully intersect. Fig. 2 summarizes the three pathways as well as their interdependencies.

\subsection{Problem identification and agenda setting}

Sustainability problems are "wicked": They are highly complex, characterized by uncertainty, and involve value divergence between different stakeholders (Head, 2008; Van der Brugge et al., 2005). Thus, problems need to be identified and structured, and decisions have to be made about the direction of efforts to develop new scientific knowledge and technologies (Loorbach et al., 2017; Smith et al., 2010).

In traditional academic research, the identification and prioritization of research questions is driven primarily from within the academic community based on factors such as perceived scientific impact and value judgments of professional peers (Latour, 1987; Sauermann and

\section{Problem identification and agenda setting}

- Citizen perspectives help identify and frame sustainability problems.

- Participation in agenda setting helps negotiate and align the interests of multiple publics.

Resource mobilization

- Citizens contribute effort towards research.

- Citizens contribute technical knowledge and solutions, as well as understanding of sociopolitical aspects and constraints.

\section{Facilitating socio-technical} co-evolution

- CS helps generate solutions that address technical as well as social aspects of sustainability problems.

- CS participation facilitates citizen learning about problems and solutions; behavioral changes.

- CS participation motivates and enables citizens to advocate for socio-political changes.

Fig. 2. Three pathways of Citizen Science support for sustainability transitions, and their interdependencies. 
Stephan, 2013). In STs, however, these processes unfold in a decentralized manner and involve constellations of multiple actors, including potential users (Boon et al., 2011; Kuhlmann and Rip, 2018; Mowery et al., 2010). For example, pressure from citizens and merchants was instrumental in focusing researchers' attention on addressing public sanitation in the 19th century (Geels, 2006) and, more recently, on the development of alternatives to harmful CFC coolants in household appliances (Van de Poel, 2003). Various stakeholder groups were also involved in shaping the discourse on problems with Dutch water management and in identifying more sustainable approaches (Van der Brugge et al., 2005).

We suggest that Citizen Science can play an important role in identifying and structuring problems as well as in setting research agendas based on diverse stakeholder needs. One approach is to cocreate projects and involve citizens in all aspects of research, including the identification of research questions. Consider the example of a project led by the Extreme Citizen Science research group at the University College London, which collaborated with herders and farmers in Kenya to study ecosystem change and preserve local ecological knowledge (ExCiteS, 2019). The UCL scientists spent considerable time with the local community to discuss what problems it faced and to brainstorm how the available UCL technical infrastructure for data collection and monitoring might help citizens to study and address their problems. Among others, the citizens used their knowledge about the local ecosystem to identify 134 plant species that needed to be monitored. Based on their understanding of the socio-political context, they also identified the need for mechanisms to share the data with each other and with regional partners in order to facilitate decision-making. The citizens then participated actively in the development of the project infrastructure (e.g., by taking the sample photos used for identification) as well as in the actual data collection.

A second approach is to ask citizens specifically to identify problems, without involving them in other stages of the research. For example, an Austrian research foundation seeking to award research funding reached out to citizens to identify understudied research questions in health. A first iteration of this project focused on mental health and received input from hundreds of citizens, including patients and doctors (Ludwig Boltzmann Gesellschaft, 2018). Illustrating the benefits of involving the broader public, the winning questions addressed important problems that were not at the core of scientific research at that time, such as the mental health of children and adolescents. Similarly, citizens drew attention to the social dimensions of health issues, asking not just how illnesses can be cured or managed (the focus of prior research) but also how the social stigma of mental illnesses can be reduced if a cure is not possible. Several of the proposed research questions are now being investigated. The latest iteration of this project focuses on traumatology research (Beck et al., 2019), and the project title "Tell us" (Fig. 3) illustrates how the approach to ask citizens for input in the problem definition stage goes well beyond the traditional "deficit model" of science-society interactions, where problems are chosen by experts and solutions simply communicated to a non-expert public (Irwin, 2014).

Third, and most closely aligned with the "democratization view" of CS, citizens can take initiative without the leadership of professional scientists. Callon and Rabeharisoa (2008) describe how a French patient organization concerned with muscular dystrophy initiated research by building a researcher community, providing funding for scientists, building dedicated research infrastructure, and getting directly involved in research projects. Similarly, the Catalan Mental Health Federation, which unites people with mental health problems and their relatives, encouraged a group of scientists to join in a CS project to study and support community-care approaches in a participatory manner (Cigarini et al., 2018). Finally, the Ringland Academy, a think tank within the Ringland citizen movement, promoted research on traffic-related emissions by initiating the project "CurieuzeNeuzen", which systematically measured air quality in the Belgian city of
Antwerp (Van Brussel and Huyse, 2018). It secured the necessary resources through crowdfunding and enlisted researchers from local universities and research institutes as professional collaborators in the project.

Although these examples illustrate how citizens can identify and direct research efforts towards sustainability problems, they also highlight that problems are not universal but reflect the interests and needs of particular groups of citizens. ${ }^{9}$ Moreover, although "sustainability" is often used as a general term, different sustainability goals can conflict - such as the goal to preserve the natural environment and the goal to improve living standards through economic growth (Pradhan et al., 2017; Trisos et al., 2019). Indeed, the difficulty of reconciling competing interests is one of the key features of wicked problems and of the governance of sustainability transitions (Patterson et al., 2017; Rittel and Webber, 1973). The "democratization view" posits that CS democratizes science by allowing the public to shape research agendas that have traditionally been set by professionals. To the extent that these processes are transparent and involve a broad range of stakeholders, this may also help align the interests of "multiple publics" (Ribeiro et al., 2018; Stilgoe et al., 2014). Of course, citizen participation does not automatically resolve value conflicts or eliminate inherent trade-offs between different sustainability goals. As such, the impact of Citizen Science in problem framing and agenda setting processes depends critically on which citizens get involved and how representative they are of the broader population. We will return to this issue when discussing challenges in Section 4.

Citizen Science is not the only mechanism allowing citizens to shape the direction of research. The literature on public engagement in science discusses others such as roundtables or consensus conferences (Stilgoe et al., 2014). Many of these mechanisms are initiated by policy makers in order to give citizens a voice in important decisions and are moderated by professional agents (Felt and Fochler, 2008). Although a detailed comparison of the different mechanisms is beyond the scope of this paper, CS projects differ in important ways. In particular, collaborations tend to be more informal, often initiated by individual scientists seeking input from citizens or by citizens seeking help from professionals to address specific problems (Druschke and Seltzer, 2012; Van Brussel and Huyse, 2018). Participation is also more open in that people are generally not pre-selected by organizers or represent particular stakeholder groups but participate as individuals because they themselves decide to engage (Pettibone et al., 2018). Finally, interactions in CS projects do not rely on "stage-managed spaces of engagement" (Stilgoe et al., 2014, p. 7) but often involve personal interactions between citizens and scientists. Such interactions may strengthen social relationships, facilitate the open exchange of different perspectives, and improve mutual understanding (Felt and Fochler, 2008), potentially resulting in a more effective identification of research areas where the interests and capabilities of scientists intersect with the needs of the broader public (Senabre et al., 2018). The contrast to public engagement exercises is perhaps clearest for "autonomous" Citizen Science projects that proceed without involvement of professionals or policy makers, turning citizens from providers of opinions and feedback to actors who take matters in their own hands.

\subsection{Resource mobilization}

Sustainability transitions require significant human and financial resources for scientific research and technological development but also for the socio-political processes that are an integral part of transitions (Hekkert et al., 2007). These resource requirements are evident in

\footnotetext{
${ }^{9}$ By drawing attention to particular sustainability problems, CS may also draw attention to sustainability problems in general (vs. problems of purely scientific interest). It appears that the latter typically operates via the former, so we focus on the former.
} 


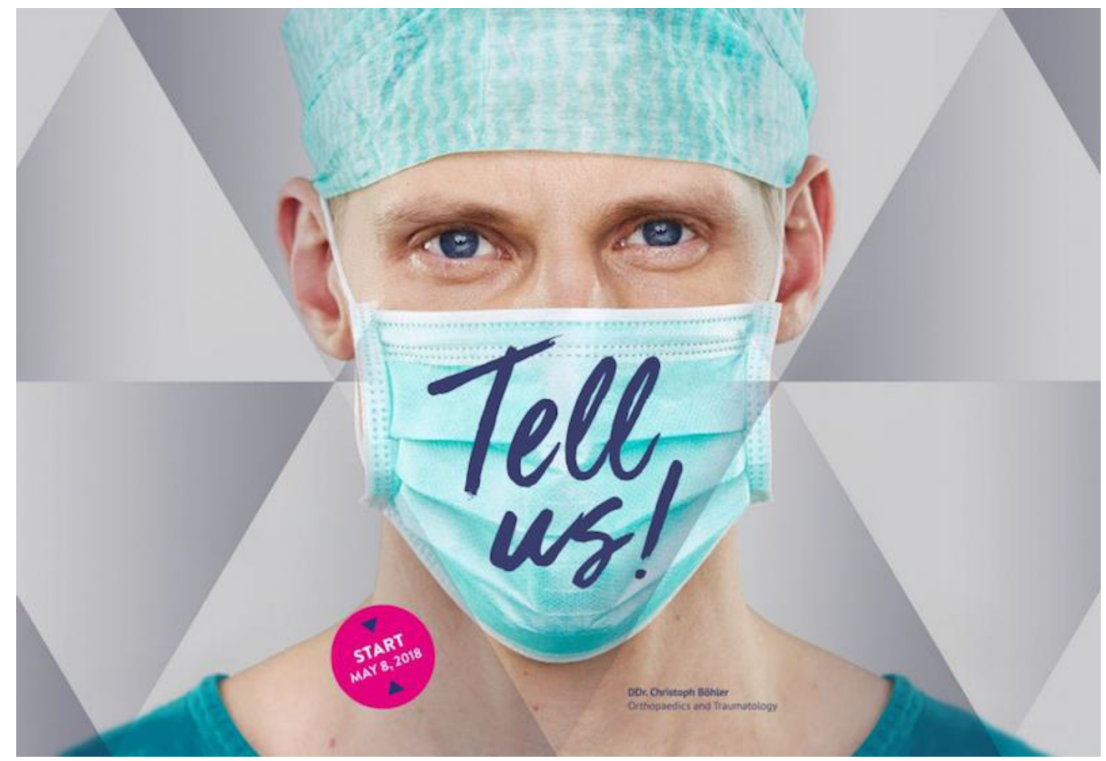

Fig. 3. Poster for "Tell us" project to crowdsource research questions in science. Source: https://ois.lbg.ac.at/en/methods-projects/cris.

examples such as the transformation of Dutch water management, the development of alternative energy sources, or the re-configuration of personal transportation systems (Fagerberg, 2018; Geels, 2002; Van der Brugge et al., 2005). However, the high uncertainty and complexity associated with STs can discourage the necessary investment, preventing research from being done or constraining the emergence of technical solutions beyond experimental niches (Geels, 2002, 2006).

We suggest that Citizen Science can support sustainability transitions by mobilizing resources. First, as highlighted by the "productivity view" of CS, large numbers of contributors can provide human effort that speeds up research or enables large-scale projects that would be difficult to perform with the resources available in the traditional scientific system. For example, participants on the Citizen Science platform Zooniverse have contributed effort valued at millions of dollars towards research on astronomy, medicine, and climate change by classifying images (Sauermann and Franzoni, 2015). CS projects are particularly effective in collecting large amounts of observational data across space and time. The Cornell Lab of Ornithology, for example, has developed a portfolio of highly successful Citizen Science projects that involve over 400,000 participants. These projects have contributed data for over 150 scientific papers on topics such as changes in bird migration patterns, the impact of non-native species, biological diversity, and climate change. ${ }^{10}$ We already mentioned the CurieuzeNeuzen project, which was able to collect very detailed air quality information that allowed climate scientists to validate and improve existing computer models (see Fig. 4).

Second, while many studies focus on participants' contributions of effort, citizens can also contribute unique technical skills and knowledge. As shown in prior innovation research, a diversity of knowledge inputs tends to increase the quality of solutions, and broadcasting problems to a wide range of people increases the chance of finding someone who has the required skills or insights (Jeppesen and Lakhani, 2010). An example is the project Foldit, which used citizens' spatial capabilities to solve the structure of enzymes that are critical for the reproduction of the AIDS virus and to improve traditional computer algorithms for predicting the molecular structure of proteins (Khatib et al., 2011). In another example, the platform InnoCentive broadcast a call for solutions to help clean up remaining pollution from the Exxon Valdez oil spill. The winning solution came from John Davis,

\footnotetext{
${ }^{10}$ http://www.birds.cornell.edu/page.aspx?pid $=1664$
}

who drew on his experience in the concrete industry to come up with a creative solution to prevent the freezing of oil in arctic waters (Innocentive, 2007).

In the context of sustainability transitions, citizens can also contribute another type of knowledge: Knowledge about socio-political conditions that are relevant for understanding and addressing sustainability problems. Among others, citizens involved in research may identify challenges with respect to the social acceptance of solutions and may draw greater attention to potential adverse impacts of new scientific knowledge and technologies. This can enable projects to proactively address some of those concerns, resulting in more responsible and socially robust innovation (Boon et al., 2011; Nowotny, 2003; Stilgoe et al., 2013). Consider the example of academic scientists who sought to address the problem of overgrazing on the Greek island of Samothraki (Petridis et al., 2017). Close collaboration with local farmers allowed the scientists to study the biological aspects of overgrazing. More importantly, it helped them understand the underlying economic incentives and constraints the farmers faced. As a result, the project devised solutions that addressed not only technical but also social aspects of the problem. Prior research on crowdsourcing and user innovation suggests that the rich contextual knowledge citizens have about problems and potential solutions is often "sticky", i.e., hidden from professional scientists and difficult to transfer (Ottinger, 2010; Poetz and Schreier, 2012; Von Hippel, 1994). As such, direct involvement of citizens in research and innovation is often necessary to take advantage of this knowledge.

This discussion yields an important insight about Citizen Science in the particular context of sustainability transitions: Citizens will often be more than anonymous suppliers of labor or ideas; their personal experiences and backgrounds matter, and their preferences and assumptions can shape the process of research and the solutions that emerge (Parrish et al., 2019). Some CS projects minimize such influences by standardizing processes and limiting citizens' contributions to small micro-tasks. To create knowledge that can address socio-technical sustainability problems, however, projects will often have to acknowledge and embrace such influences, while recognizing potential goal conflicts and biases. We will expand upon this challenge in Section 4 below.

The pathway of resource mobilization described in this section likely interacts with problem identification and agenda setting (see Section 3.1). For one, the experiential knowledge resources that citizens contribute affect how problems are framed and how visions for 


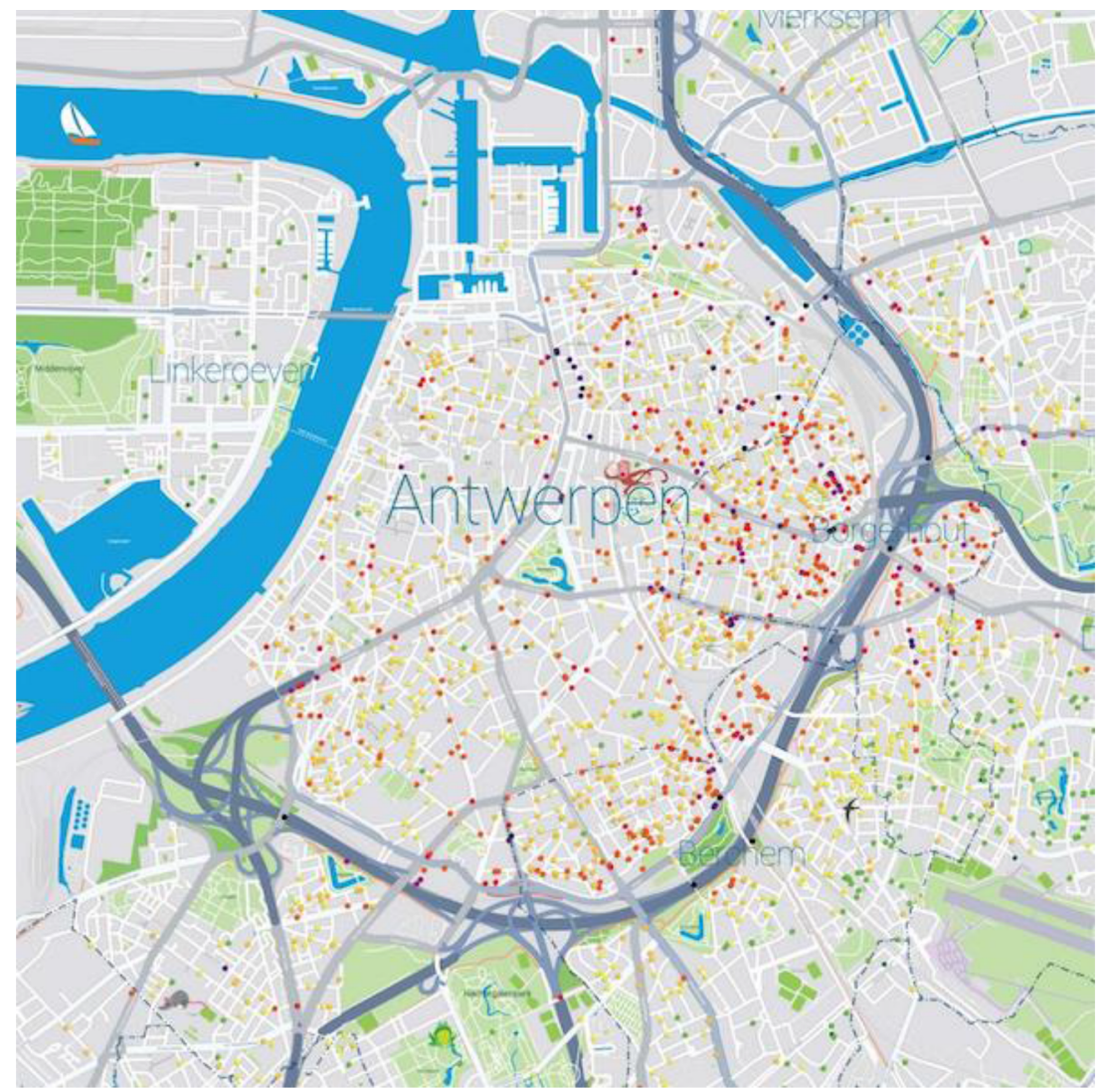

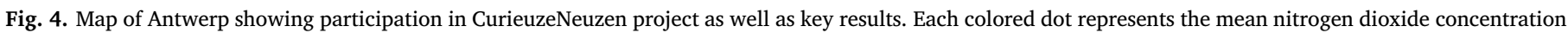
at a measuring location in May 2016. Source: https://curieuzeneuzen.be/in-english/.

solutions are developed. Moreover, stakeholders who contribute more resources likely have a greater influence in the political processes that shape agenda setting. Indeed, organizations such as the CurieuzeNeuzen project or the French Association of Muscular Dystrophy Patients mentioned above were arguably able to influence the direction of research precisely because they brought their own resources to bear, which made them less dependent on other stakeholders. Finally, citizens will be more willing to contribute time and other resources to projects that align with their interests or that promise to address their own problems (Geoghegan et al., 2016; Sauermann and Franzoni, 2013). ${ }^{11}$ As such, citizen involvement in problem identification and agenda setting may also increase resource mobilization for other aspects of transition processes. ${ }^{12}$

\subsection{Facilitating socio-technical co-evolution}

Sustainability transitions such as those towards renewable energy, efficient transportation systems, or sustainable agricultural methods involve new techno-scientific solutions but also social elements (Mowery et al., 2010; Patterson et al., 2017). In particular, they require changes in norms, values, and behaviors, including the adoption of solutions by actors such as consumers and firms (Smith et al., 2005).

\footnotetext{
${ }^{11}$ When asked in our survey about potential participation in CS, several MTurk respondents made statements such as: "It depends on the project. If I am passionate about it, then I'm more likely to be involved."

${ }^{12}$ Although our focus in this section is on resource mobilization, CS may also increase the efficiency with which available resources are used. In particular, to the extent that CS projects promote transparency in research processes as well as broad access to data and research outputs, duplication of effort can be avoided and collective research output can be increased (Franzoni and Sauermann, 2014; Vohland and Göbel, 2017).
}

Moreover, transitions often depend on supportive policies such as regulations and subsidies (Geels and Schot, 2007; Smith et al., 2010). Importantly, socio-technical transitions are not linear in the sense that new technologies are first developed and then adopted; rather, technoscientific knowledge co-evolves with socio-political aspects (Edmondson et al., 2019; Head, 2008; Loorbach et al., 2017). For example, complex technologies such as sewer systems or electric vehicles are developed and refined over longer periods of time, whereby user feedback as well as political and market processes intervene in the selection of alternative technological paths (Geels, 2006; Jørgensen, 2012). At the same time, demand becomes more clearly articulated and users' preferences are shaped as they interact with emerging technical solutions. Similarly, the regulatory environment changes as risks and opportunities resulting from solutions become clearer (Rip, 1995).

Although the range of actors in sustainability transitions is wide, citizens are often critical as buyers of technical solutions, adopters of more sustainable practices and behaviors, and voters who influence regulators and policy makers (Mowery et al., 2010; Smith et al., 2005). As such, we argue that Citizen Science can support STs by increasing the alignment between techno-scientific and socio-political aspects and by facilitating their co-evolution.

First, our discussion in the prior sections suggests that citizen participation in setting research agendas and performing research will result in better solutions, whereby the quality of solutions reflects their ability to address technical aspects of sustainability problems, but also their alignment with the socio-political environment. Better solutions, in turn, will be more likely to receive support and diffuse. Consider again the Samothraki CS project on overgrazing, which resulted in a socio-technical solution that farmers found worth adopting (Petridis et al., 2017).

Second, in addition to shaping what solutions emerge, Citizen 
Science can lead to changes in participants' knowledge and attitudes. In particular, participation in research can build awareness and allow citizens to gain a clearer understanding of sustainability problems (Brossard et al., 2005). This is particularly valuable in areas where problems are abstract (e.g., biodiversity loss), intangible (global warming) or invisible (nuclear radiation). Participation in research can also increase citizens' familiarity with particular subjects and enable them to better assess the merits and risks of techno-scientific solutions (Ball et al., 2014; Jordan et al., 2011).

Increased awareness and learning, in turn, may change behaviors. For one, participants who gain awareness of sustainability problems are often more motivated to help solve them (Crall et al., 2012; Toomey and Domroese, 2013). An example is the German project ReparaKultur, which created repair cafés and brought together citizens and social scientists to reflect on their relationships with consumer products. Partly as a result of increased awareness of sustainability problems related to overconsumption, this project led to changes in participants' patterns of purchasing and re-use (Hielscher and JaegerErben, 2019). Relatedly, citizens who have personally contributed to solutions and who have in the process learned about their scientific rationale may be more likely to adopt them.

Third, greater awareness of problems, a better understanding of socio-technical solutions, as well as a personal stake in those solutions can lead citizens to push for complementary changes through interactions with policy makers or other stakeholders (Kythreotis et al., 2019). CS can be particularly effective in the latter respect if it allows citizens to produce scientific evidence on sustainability problems or solutions. For example, a recent German CS project documenting a dramatic drop in insect biomass has attracted global attention (Hallmann et al., 2017; McGrane, 2017) and exerted policy pressure that may well exceed the pressure created by an extensive report on pollinators by the Intergovernmental Science-Policy Platform on Biodiversity and Ecosystem Services (Potts et al., 2016). Such influence is reinforced by a shift in the policy community towards accepting new modes of public participation including Citizen Science (Kuhlmann and Rip, 2018).

The CurieuzeNeuzen project illustrates several of the mechanisms discussed in this section (Van Brussel and Huyse, 2018). This project involved almost 2000 residents in measuring air quality across the city of Antwerp. In addition to receiving valuable data, the organizers also documented changes in participants' awareness of pollution problems and in attitudes towards public policies and infrastructure projects. Moreover, participants reported in a post-project survey plans to change their own behaviors, including using cars less frequently and approaching government officials about air quality problems. This project drew national media attention that increased its impact beyond project participants. Potential "coalition partners" (Smith et al., 2005) such as politicians supporting more sustainable modes of transportation publicly endorsed the project, and the data and scientific results have been considered in local policy decisions. ${ }^{13}$ Of course, this project also reminds us of the political nature of CS in the context of sustainability transitions: By stimulating research on particular problems such as air pollution, projects can deflect attention of citizens and policy makers from other problems (e.g., poverty reduction). ${ }^{14}$ Moreover, the solutions that are developed to address a focal problem may have negative

\footnotetext{
${ }^{13}$ The AIRbezen project uses a different technology to measure air quality and had roughly 10,000 participants in 2017. Project findings were used by the Belgian senate in a report on policy measures for improving air quality (see www.airbezen.be).

${ }^{14}$ Research is needed on whether and how CS efforts in one domain "crowd out" efforts in other domains (for some evidence on interdependencies between individual projects see Sauermann and Franzoni, 2013). Up to a certain point, there may be positive spillovers in that successful projects legitimize and draw attention to CS in general. To the extent that attention of citizens and policy makers is limited, however, increasing activity in one domain may ultimately reduce activity in others.
}

implications for some external stakeholders (e.g., people living outside the city and relying on their cars to commute to work).

How does the potential role of Citizen Science differ from that of other mechanisms to increase science-society interactions, including "public engagement with science", "public understanding of science", and "science communication" (Felt and Fochler, 2008; Jasanoff, 2003; Stilgoe et al., 2014)? While there are many overlaps, we argue that CS differs because it involves citizens in the actual production of scientific knowledge rather than just informing and educating about this production or its results. As such, it provides greater potential for citizens to shape and improve solutions, supporting the co-evolution of social and technical aspects. Moreover, active participation is "experiential", with greater opportunities for learning (Kolb and Kolb, 2005). The direct collaboration between professional scientists and citizens also fosters closer personal relationships that enable deeper understanding (Felt and Fochler, 2008). Finally, participation in different stages of the research process - including the formulation of research questions likely creates stronger ownership of problems and potential solutions (Geoghegan et al., 2016), which can motivate citizens to advocate for broader socio-political changes. This discussion highlights connections between this third pathway and the two we discussed earlier: CS can facilitate the co-evolution of techno-scientific and socio-political aspects partly because citizens get involved in identifying sustainability problems and setting research agendas (pathway 1) and because they contribute to research with their time, effort, and experiential knowledge resources (pathway 2). At the same time, participants' assessments of the degree to which socio-technical alignment is (not) being achieved may feed back into agenda setting and resource mobilization activities (see Fig. 2).

\section{Challenges}

Section 3 identified considerable opportunities for Citizen Science to support sustainability transitions. To realize this potential, however, CS needs to overcome a number of challenges. Just like the opportunities, these challenges relate to a large extent to the fact that STs are of a socio-technical nature, and that supporting them requires the integration of two quite different "views" of Citizen Science. The three challenges we highlight in the following flow from our discussion of opportunities, while also reflecting prior research on Citizen Science and extensive discussions with project leaders and participants (see Section 1). Table 2 summarizes the challenges and identifies connections with the three pathways identified in Section 3.

\subsection{Increasing the diversity, level, and intensity of participation}

\subsubsection{The importance of participation}

Our discussion thus far was based on the premise that projects involve citizens from diverse parts of society (e.g., with respect to socioeconomic status, race, and gender) who make contributions that are significant in volume and sustained over time. The diversity of participants is relevant for all three pathways: When citizens get involved in identifying problems and setting research agendas, their identity will shape what projects are pursued. If participants are not diverse and representative of the broader population, research agendas will reflect primarily the preferences and assumptions of those who participate rather than society at large, contrary to the premise of the "democratization view" of CS (English et al., 2018; May et al., 2014). Diversity among participants is also likely to increase the diversity in knowledge resources and thus creativity in generating problem solutions, as well as the alignment between technical and social aspects (Cigarini et al., 2018; Horwitz and Horwitz, 2007). Finally, diversity in participation will generate broader benefits in terms of learning and buy-in and may thus contribute to the wider diffusion of emerging solutions and complementary socio-political changes.

A high level of participation - in terms of the number of participants, 
Table 2

Potential challenges for Citizen Science in supporting sustainability transitions.

\begin{tabular}{|c|c|c|c|}
\hline Challenge & Relevance for agenda setting & Relevance for resource mobilization & Relevance for socio-technical co-evolution \\
\hline $\begin{array}{l}\text { Increasing participation (diversity; } \\
\text { level; intensity) }\end{array}$ & $\begin{array}{l}\text { Lack of diversity among participants limits } \\
\text { the range of sustainability problems that } \\
\text { are addressed (e.g., biodiversity vs. } \\
\text { poverty) and limits the "democratizing" } \\
\text { potential of CS in agenda setting. } \\
\text { - Low level and intensity of participation } \\
\text { limit the weight of CS initiatives in the } \\
\text { politics of agenda setting. }\end{array}$ & $\begin{array}{l}\text { Low level and intensity of } \\
\text { participation limit the volume of } \\
\text { effort and knowledge resources } \\
\text { mobilized for CS projects. }\end{array}$ & $\begin{array}{l}\text { Lack of diversity leads to solutions that } \\
\text { fail to align technical and social elements } \\
\text { (e.g., fail to consider the constraints of } \\
\text { economically disadvantaged citizens). } \\
\text { - Low level and intensity of participation } \\
\text { limit learning and awareness in the } \\
\text { broader public, thus the motivation and } \\
\text { ability to adopt emerging solutions and } \\
\text { advocate for socio-political changes. }\end{array}$ \\
\hline $\begin{array}{l}\text { Addressing the social as well as } \\
\text { technical nature of sustainability } \\
\text { transitions (diverse research } \\
\text { topics; scientific and non-scientific } \\
\text { project goals) }\end{array}$ & $\begin{array}{l}\text { Single-disciplinary perspectives (e.g., } \\
\text { natural vs. social sciences) focus on a } \\
\text { limited range of research questions and fail } \\
\text { to address interactions between social and } \\
\text { technical elements. }\end{array}$ & $\begin{array}{l}\text { Narrow range of research } \\
\text { questions and project goals limits } \\
\text { the interest of the broader public } \\
\text { and thus resource mobilization. }\end{array}$ & $\begin{array}{l}\text { Solutions that only address technical } \\
\text { aspects of sustainability problems are } \\
\text { less likely to emerge beyond } \\
\text { experimental niches. }\end{array}$ \\
\hline & $\begin{array}{l}\text { - Perceived trade-offs may lead to the } \\
\text { exclusion of "secondary" non-scientific } \\
\text { project goals that are important for } \\
\text { transitions. }\end{array}$ & $\begin{array}{l}\text { - Unresolved trade-offs between } \\
\text { project goals (e.g., between citizen } \\
\text { learning and knowledge } \\
\text { production) lead to inefficient } \\
\text { resource utilization. }\end{array}$ & $\begin{array}{l}\text { - If non-scientific project outcomes are } \\
\text { ignored, socio-political and techno- } \\
\text { scientific aspects of sustainability } \\
\text { transitions fail to co-evolve. }\end{array}$ \\
\hline $\begin{array}{l}\text { Reducing tensions between CS and the } \\
\text { institution of academic science } \\
\text { (autonomy vs. control; } \\
\text { performance metrics) }\end{array}$ & $\begin{array}{l}\text { Norms of scientific autonomy deter } \\
\text { professional scientists from sharing control } \\
\text { with citizens when setting research } \\
\text { agendas. } \\
\text { Narrow academic performance metrics } \\
\text { prevent scientists from pursuing social } \\
\text { impact outcomes that are long-term, } \\
\text { uncertain, and difficult to measure. }\end{array}$ & $\begin{array}{l}\text { Concerns about external influence } \\
\text { reduce scientists' willingness to } \\
\text { rely on citizens' effort and } \\
\text { knowledge resources. } \\
\text { - Narrow performance metrics lead } \\
\text { scientists to ignore potential } \\
\text { contributions that do not translate } \\
\text { into scientific productivity. }\end{array}$ & $\begin{array}{l}\text { Lack of control limits citizens' ability to } \\
\text { shape solutions and their motivation to } \\
\text { advocate for socio-political changes. } \\
\text { - Traditional performance metrics } \\
\text { promote the "productivity view" of CS, } \\
\text { failing to facilitate the co-evolution of } \\
\text { social aspects. }\end{array}$ \\
\hline
\end{tabular}

as distinct from their diversity - is also important. Large numbers of participants may have a greater weight in political processes associated with problem identification and agenda setting. Large volumes of contributions increase the chances of generating valuable knowledge and solutions, and such benefits of scale exist across a broad range of activities including both data collection and analysis as well as creative tasks and problem solving (Sauermann and Franzoni, 2015; Simonton, 2003). Finally, the more people participate in Citizen Science projects, the more widespread can be the benefits of learning, potentially resulting in increased motivation to adopt emerging solutions and advocate for complementary socio-political changes (Kythreotis et al., 2019; Ruckart et al., 2019).

Third, the pathways we identified likely benefit from a high intensity of participation, i.e., the extent to which given citizens are involved in a project at a point in time and such involvement is sustained over time. Although intensive participation is not required to collect initial ideas regarding sustainability problems or potential solutions (Beck et al., 2019), deeper involvement is likely beneficial for citizens to bring to bear their tacit experiential knowledge and preferences when framing problems or creating shared visions about possible futures (Felt and Fochler, 2008; Head, 2008). Sustained participation over time is required for certain types of knowledge contributions such as longitudinal observational data and is also beneficial for citizen learning (RuizMallén et al., 2016).

\subsubsection{Current participation patterns}

Many Citizen Science projects fail to attract enough participants, participants tend to engage with projects only briefly, and even successful projects rely on a small share of contributors who do most of the work (Dickinson and Bonney, 2012; Sauermann and Franzoni, 2015). Projects also often do not involve a representative cross-section of society: They tend to attract individuals with higher levels of education and pre-existing interest in science (Raddick et al., 2013; Van Brussel and Huyse, 2018), older, white, educated men (Ganzevoort et al., 2017), or middle-aged white persons with above average income (Geoghegan et al., 2016; Haklay, 2015). Indeed, this lack of diversity may partly explain why many CS projects focus on environmental sustainability or health, but few address sustainable development goals such as "no poverty" or "zero hunger".

Several factors may shape current participation patterns. With respect to the diversity of participants, projects led by professional scientists often make limited efforts to reach underrepresented groups and instead rely on self-selection and individuals' intrinsic motivation to participate (Raddick et al., 2013). Even if projects are initiated by citizens, participants tend to represent selected groups that have a strong interest in a particular topic or sustainability problem (McCormick, 2007; Ottinger, 2010). To some extent, this may reflect that recruiting efforts targeted at individuals who are predisposed towards science (e.g., at science fairs) or who care about particular problems are more successful than efforts to draw in participants from other strata of society. But under-representation may also reflect important constraints certain individuals face. In particular, even though new digital platforms and portable technologies such as smartphonebased measurement tools can enable greater participation, they are not universally accessible and can pose barriers for individuals with lower levels of income and education, or for older individuals who experience difficulties operating new technologies (West and Pateman, 2016). Similarly, time commitments for CS may be difficult to make by individuals in certain life stages and socioeconomic groups, such as parents with young children or individuals working multiple jobs. ${ }^{15}$

With respect to the level and intensity of participation, some projects struggle to attract participants and keep them engaged because they are too demanding in terms of skills or subject-related knowledge (Crowston and Fagnot, 2008). Limited participation can also reflect low interest and motivation, e.g., because participants see no personal relation to a scientific problem (Bela et al., 2016). Moreover, initial

\footnotetext{
${ }^{15}$ When asked about reasons (not) to participate in CS, one MTurk respondent commented: „I am disabled and only have a limited amount of energy every day to spend on silly things like showering, taking care of my fosters etc. so I would have to gauge the pro and con carefully... If I could even be valuable." Another: "If I have time and find one that's interesting I'll participate, but right now I just need to make sure I can keep my lights on and food on the table."
} 
motivation often decreases over time as the novelty of Citizen Science participation fades, or as opportunities for learning and discovery seem to decline (Sauermann and Franzoni, 2013; West and Pateman, 2016).

\subsubsection{Potential mechanisms to increase participation}

Emerging evidence points towards promising approaches to increase participation. For example, studies suggest that people are more engaged in projects when they receive clear guidelines how to use simple methods within a well-defined time-frame (Couvet and Prevot, 2015; Hyder et al., 2017). Projects also attract more contributors when benefits to participants are integrated into the project design (Senabre et al., 2018; Shirk et al., 2012). The motivation to participate tends to be high when projects address concrete sustainability problems such as air pollution in a specific location (e.g., Van Brussel and Huyse, 2018), or in domains with high levels of hobbyist interest such as ornithology and astronomy. Alternatively, some projects have increased participation by "gamifying" less interesting tasks (Eveleigh et al., 2013). Other projects have been able to maintain and even increase individuals' engagement over time by offering "career ladders" that start with easy tasks but allow participants to move to more complex tasks with higher responsibility. On the platform Zooniverse, for example, this includes tasks such as moderating a discussion forum or helping resolve disagreements over images that are difficult to classify (Jackson et al., 2016).

Projects can seek to increase diversity by reducing barriers posed by expensive technologies, e.g., by lending out camera traps through public libraries ${ }^{16}$ or by allowing participants to send data through smartphone apps as well as postal mail. Moreover, projects can make efforts to reach out to under-represented populations with relatively simple means, e.g., by considering diversity when selecting promotional pictures of participants for brochures and project websites (West and Pateman, 2016).

Despite these promising mechanisms, there are also potential tradeoffs between different aspects of participation. For example, simplifying tasks and lowering skill and time requirements may attract more participants but can reduce their intensity of engagement (Hackman and Oldham, 1976). Similarly, the (online) project infrastructure required to enable large-scale participation likely limits opportunities for personal interactions and learning, potentially reducing the intensity of engagement. Finally, efforts to increase diversity by reaching out to populations that do not naturally self-select (e.g., those with lower interest in science or lower income) will be costly and likely yield a lower number of participants as well as lower intensity of engagement. To the extent that these trade-offs are difficult to resolve, organizers may have to prioritize aspects of participation depending on the nature of the scientific problem and in light of non-scientific project goals (see next section).

\subsection{Addressing the socio-technical nature of sustainability transitions}

The socio-technical nature of sustainability transitions creates unique opportunities for Citizen Science (discussed in Section 3), but also challenges. In the following, we will first discuss the challenge to include both technical and social aspects as topics of CS investigations, followed by the challenge to pursue both scientific and non-scientific project goals. We then consider the potential role of project governance in addressing both challenges. We note that some readers, especially those who study socio-technical transitions or who subscribe to the "democratization view" of CS, may argue that distinctions between social and technical aspects, or between scientific and non-scientific project goals are misleading since these aspects should not be separated. To the extent that we use terminology that implies such distinctions, we do so for analytical purposes and because many

\footnotetext{
${ }^{16}$ http://www.nccandidcritters.org
}

discussions of the institution of science and of Citizen Science do draw these distinctions. At the same time, the prominence of these distinctions especially among professional scientists - as evidenced, for example, in the disciplinary organization of academic departments - may exacerbate some of the challenges we are about to discuss.

\subsubsection{Investigating technical as well as social aspects of sustainability problems}

Sustainability problems have multiple causes that cut across academic disciplines, requiring corresponding breadth in the issues that are studied. Similarly, citizens can contribute knowledge about technoscientific aspects (e.g., data on bird locations or air quality) but also knowledge about socio-political aspects of problems (Nowotny, 2003; Smith et al., 2005). As such, both technical and social aspects need to be considered when framing sustainability problems and setting research agendas, and when integrating citizens' resources.

Although Citizen Science provides the opportunity to integrate research on natural and social phenomena (Crain et al., 2014), CS projects often pursue either technical or social topics, partly reflecting the disciplinary backgrounds and interests of academic project organizers. Moreover, attention is unbalanced: Citizen Science is gaining traction quite rapidly in the natural sciences, while adoption among social scientists - and thus attention to social aspects of sustainability transitions - remains limited (Crain et al., 2014; Kullenberg and Kasperowski, 2016). The reasons for the latter are likely multi-faceted, including a longer history of citizen involvement in studying the natural environment than in studying social processes, greater agreement on research questions and methods in the natural sciences, as well as fewer concerns regarding data protection and research ethics (Heiss and Matthes, 2017). Despite these challenges, multi-disciplinary collaborations between scientists as well as citizens can succeed in addressing sustainability problems. For example, joint leadership of the Samothraki Citizen Science project by environmental and social scientists was partly responsible for its ability to design effective solutions (Petridis et al., 2017).

\subsubsection{Pursuing scientific as well as non-scientific project goals}

The socio-technical nature of STs requires attention to scientific outcomes but also non-scientific goals such as learning and advocacy. In particular, we argued in Section 3 that citizens' learning about sustainability problems and about the research process can allow them to make greater contributions to knowledge generation, while also fostering the co-evolution of socio-political aspects. However, the evidence on learning outcomes is mixed (Groulx et al., 2017). On the one hand, research shows that project participation can increase citizens' topical knowledge and awareness of the ecosystem (Mueller et al., 2012; Senabre et al., 2018). On the other hand, evidence regarding the effects on participants' attitudes or learning about the scientific process is inconclusive, with some studies finding benefits (Ballard et al., 2017; Cronje et al., 2011) and others finding no changes (Brossard et al., 2005; Crall et al., 2012; Jordan et al., 2011).

There are several potential reasons for limited participant learning. One relates to the observation that many citizens participate in projects only with low intensity (see Section 4.1); this limited engagement is unlikely to provide the depth of exposure to science and the rich interactions with professional scientists that may be most useful in stimulating mutual learning. Another is that many project organizers, especially those subscribing to the "productivity view", focus on scientific outputs of CS and pay little attention to learning goals (Bela et al., 2016; Groulx et al., 2017). But even projects that make serious efforts to accomplish learning goals may use methods that turn out to be ineffective. For example, organizers of the Chicago Area Pollinator Study handed out a highly researched and colloquially written information sheet to educate participants about different types of bees. After the observed improvements in knowledge failed to meet organizers' expectations, they conjectured that interactive blogs and 
personal feedback on participants' submissions of specimens might have been a more effective approach (Druschke and Seltzer, 2012).

The Chicago Area Pollinator Study highlights the more general issue that there are often difficult trade-offs between scientific and educational goals. In particular, the organizers had to recognize that the work required to process large amounts of submissions left them little time to provide mentoring and personalized learning experiences to participants (Druschke and Seltzer, 2012). Similarly, many CS projects use relatively rigid protocols and automated processes in order to accommodate large numbers of participants and to ensure the quality of data and results. Such standardized processes may reduce participants' opportunities to ask questions or engage actively with project leaders, limiting learning opportunities. On the other hand, scientific and educational goals can also be synergistic. For example, achieving learning goals can increase participants' ability to make higher quality scientific contributions to a project, potentially increasing scientific output (Parrish et al., 2019). Similarly, citizen learning can increase motivation and thus the volume of contributions (Geoghegan et al., 2016).

Trade-offs may also exist between scientific and advocacy goals. One concern is that activists who seek to promote a particular cause may participate in CS projects primarily to generate data supporting their case and may have little interest in publishing results in the peerreviewed literature, or to critically assess the validity of results that happen to support their case. Participants who do not like particular project findings may even steer activity in other directions or selectively challenge scientific points on political grounds (Jasanoff, 2003; Lewandowsky et al., 2016). As a result, scientific results may be compromised. This trade-off may be mitigated, however, to the extent that scientifically valid results are seen as more convincing by policy makers and skeptics, ultimately increasing a project's effectiveness also with respect to advocacy. Future research is needed on the presence and magnitude of goal trade-offs and on mechanisms that allow projects to better accomplish scientific as well as non-scientific goals.

\subsubsection{The role of project governance}

The foregoing discussion raises the fundamental question of who defines CS project topics as well as goals and operational structures. At the moment, many projects are initiated and led by professional scientists working in academic environments (Bio Innovation Service, 2018; Science Europe, 2018). This raises the concern that professional scientists may frame projects primarily in terms of traditional disciplinary boundaries (e.g., natural vs. social sciences) and focus on productivity in terms of knowledge production rather than learning or socio-technical alignment. At the same time, common assumptions about professional scientists may be too simplistic: Although publications and scientific credit are important, scientists also have other motives, including social impact, sharing the passion for research with others, education, and even advocacy (Cohen et al., forthcoming; Collins and Pinch, 2012; Grundmann, 2013; Turrini et al., 2018). Moreover, scientists differ with respect to their values and interests (Sauermann and Roach, 2014), and those who lead CS projects are likely the ones who place greater value on social impact or science education (Druschke and Seltzer, 2012; Petridis et al., 2017). Nevertheless, it is likely that exclusive leadership by professional scientists makes it more difficult for projects to bridge disciplinary boundaries or to address both scientific and non-scientific goals.

To the extent that professional scientists and citizens bring different substantive perspectives as well as goals to the table, the perhaps most promising approach to better address the socio-technical nature of sustainability problems is the co-creation of projects. As per our discussion in Section 2, co-created projects involve citizens and professional scientists in all stages of the research, including the formulation of research questions as well as the design of experiments and project infrastructure. Ruiz-Mallén et al. (2016) demonstrate potential benefits of this approach by showing significant participant learning in a project that allowed citizens to identify research questions they found relevant and involved them in co-designing mechanisms to support their own learning. Although systematic evaluations of CS co-design approaches are lacking, we conjecture that co-design has benefits not only in terms of a greater ability to address socio-technical aspects of sustainability transitions, but may also help address the first challenge discussed earlier: Broadening participation and increasing the motivation of citizens to contribute their effort and knowledge resources (English et al., 2018).

Of course, even co-design will not resolve all trade-offs between project goals, and the framing of projects may remain contested between different groups of participants. To the extent that there are strong trade-offs that are difficult to reconcile within a given project, multiple goals might be accomplished across different projects. For example, while some Citizen Science projects may treat the scientific work merely as a setting to accomplish experiential learning, others may focus on the scientific outcomes and de-emphasize learning. Collectively, these projects could still support STs through the different pathways depicted in Fig. 2.

\subsection{Understanding and reducing tensions with traditional academic science}

Our discussion of goal conflicts and project governance leads us to a final challenge: Tensions between Citizen Science and traditional academic science. In the following, we focus on two aspects that are particularly salient in the context of sustainability transitions: Tensions between the norm of professional scientific autonomy and the influence of non-professional citizens, and tensions between narrow performance metrics of academic institutions and the multi-dimensional objectives of CS.

\subsubsection{Scientific autonomy $v$ s. external influence}

In the ideal-type view of academic science, researchers have autonomy in pursuing questions that they deem relevant in order to close knowledge gaps and advance the field (Jasanoff, 2003; Merton, 1973). As such, the arbiters of the value of research questions are expert scientists as well as their professional peers as reviewers of grant proposals and publications. Freedom from external control has been argued to be essential for the progress of science because external actors such as the state may have biased interests, lack the scientific expertise to assess the importance of research questions, or do not see the long-term benefits of curiosity-driven basic research (Bush, 1945; Nelson, 2004; Stokes, 1997). In an alternative interpretation, the scientific elite may insist on autonomy primarily to maintain control over material resources (Gieryn, 1983). Either way, the emphasis on autonomy goes along with a strong belief in the importance of formal education and in scientists' ability to steer the path of science for society's long-term benefit.

Citizen Science creates a tension with this postulate of scientific autonomy in that opening up projects to the public relinquishes control to non-professionals (Loorbach et al., 2017). This is clearest when citizens get directly involved in defining research questions and setting research agendas. However, researchers also give up control when relying on volunteers in contributory projects: Projects may fail to attract enough contributors (see Section 4.1), effectively giving citizens a vote on whether or not a project proceeds. ${ }^{17}$ This transfer of control is central to the "democratization view" of Citizen Science, based on the

\footnotetext{
${ }^{17}$ More subtly, scientists also give up control when allowing citizens' knowledge contributions to shape the direction of research. When asked about perceived challenges for CS, one MTurk respondent commented: "I think the biggest problem is professional scientists rejecting the discoveries made by citizens or hobbyists. Way too often, if a theory does not fit what a scientist has been taught by academia, the idea is dismissed without any further investigation, thereby losing decades of advancement that could have been made instead."
} 
implicit assumptions that citizens are better able to identify important problems for research than professional scientists and that the "votes" that are cast in this process reflect the needs of the broader public. However, many professional scientists do not share these assumptions (Simis et al., 2016), which partly explains the limited acceptance of CS among academics (Burgess et al., 2017; Golumbic et al., 2017) and is also reflected in derogatory notions such as "panda bear science" (Siva, 2014). ${ }^{18}$

The tension between scientific autonomy and influence from broader society is not new. Although professional science aspires to autonomy in theory, it has always depended on resource flows from the public, which exerts control over the general direction of research through higher-level directives from policy makers and funding agencies (Hackett, 1990; Merton, 1973). What appears to be new is that Citizen Science entails more direct and targeted influence, exerted not by elected officials or administrators but by citizens or interest groups at the level of individual projects. As such, CS creates a more decentralized, but perhaps also more politicized way through which the public shapes the direction of science.

This aspect of decentralization also points to a potential way in which the tension can be resolved: Not at the level of the overall system, but at the level of individual scientists and projects. In particular, professional scientists can choose whether they want to expose themselves to external influences by adopting Citizen Science approaches, and how much control they want to share with citizens (e.g., by participating in co-created vs. contributory projects). There is heterogeneity across scientists with respect to their concerns about autonomy and their willingness to learn from citizens, and some will get involved in CS while others will not (Geoghegan et al., 2016; Golumbic et al., 2017). Indeed, case studies suggest that many scientists who currently collaborate with citizens appreciate the interactions exactly because they change their own thinking and guide research towards greater socio-technical alignment (Petridis et al., 2017). Whether selection at the level of individual scientists will be sufficient for Citizen Science to have a significant impact on sustainability transitions partly depends on the number of professionals who are willing to share control with citizens. We are not aware of quantitative studies on this question, but there is evidence that openness towards citizen involvement is greater in the young generation of scientists (Golumbic et al., 2017; Sauermann et al., 2019), suggesting that attitudes may shift over time.

\subsubsection{Narrow performance metrics of academic institutions}

A second tension arises if academic employers prioritize scientific knowledge codified in peer-reviewed publications but Citizen Science projects reduce scientists' publication productivity due to time spent on other goals such as education or advocacy. The topics that are most likely to yield top-tier publications may also not be the same topics that promise the greatest contributions to solving sustainability problems. Of course, scientific and non-scientific goals may at times be complementary (see Section 4.2), and engaging with real world problems can also result in higher-impact publications (see Kline and Rosenberg, 2010). Moreover, scientists will have less of a problem reconciling CS with their academic environment if they adopt a "productivity view" rather than a "democratization view" since the former is consistent with currently dominant performance metrics (Table 1). However, a focus on productivity alone would limit Citizen Science's

\footnotetext{
${ }^{18}$ Even though CS transfers control from professional scientists to citizens, it may also enable individual scientists to pursue ideas for which the professional system does not provide sufficient resources. Consider the example of Jacquelyn Gill of the University of Maine, who lacked the funding for her project on the climate history of the Falkland Islands. She was able to perform this work by raising the required resources from citizens on the crowdfunding platform experiment.com. Results from this project then also convinced a traditional agency to fund follow-on work (Dolgin, 2019).
}

potential to support socio-technical sustainability transitions (Fig. 2). For CS to support transitions, professional scientists therefore likely face what a prominent report described as the trade-off between "career work" and "engagement work" (European Science Foundation, 2013).

There is little research studying academic institutions' responses specifically to Citizen Science initiatives, no less how such responses change over time. However, there is work on related developments such as academics' interactions with outside stakeholders as part of Responsible Research and Innovation (RRI) initiatives (Ribeiro et al., 2018; Von Schomberg, 2013) as well as academia-industry collaborations and academic entrepreneurship (Bercovitz and Feldman, 2008; Perkmann et al., 2013). CS differs from these mechanisms in important ways, such as the focus on individual citizens as partners (vs. firms or other stakeholders) as well as the direct participation of non-professionals in the research process (vs. consultation and responsiveness to outside interests). However, these mechanisms also share similarities in that they cross traditional academia-society boundaries, involve tradeoffs in terms of time spent on producing traditional research outputs vs. engaging with outsiders, and raise concerns regarding goal conflicts.

Research on these other external engagement mechanisms suggests that they have been accompanied by broadening performance standards within academia: Although publications remain the primary measure of success, universities now also value social impact and have added related criteria to tenure and promotion guidelines (Cohen et al., forthcoming). This development is partly driven by universities' hope that broader impacts have financial payoffs, e.g., in the form of patent royalties or funding from sponsored research (Perkmann et al., 2013). But it is also a response to demands from funders and other external stakeholders who need to justify public support for academic research (Krainer and Winiwarter, 2016). Indeed, funding agencies are also imposing such changes directly, e.g., by incorporating "broader impacts" in grant evaluation criteria (Davis and Laas, 2014).

It is too early to tell whether similar changes will help resolve the tension between academic performance metrics and non-scientific goals of Citizen Science projects. To some extent, scientists may be able to frame CS as one approach to generate the broader impact that is increasingly being expected by their employers. Moreover, some external stakeholders actively encourage Citizen Science, such as the European Union through funding programs directed at studying and using CS (SwafS, 2017). On the other hand, Citizen Science for sustainability may be more difficult to legitimize and incorporate into academic incentive systems than other external engagement mechanisms because it involves a greater loss of professional autonomy, which is likely to be resisted (see Section 4.3.1). Perhaps more importantly, its broader impacts are difficult to measure and document due to the complex, uncertain, and long-term nature of socio-technical transitions, as well as the important role of subjective value judgments (Section 3.1).

\section{Discussion}

Citizen Science is receiving increasing attention from scientists and policy makers. Although much has been written about the opportunities and challenges of CS in general, our novel contribution is to evaluate its potential in one very important domain: Addressing sustainability problems such as reducing poverty, improving health, and preserving the natural environment. ${ }^{19}$ Our discussion suggests that Citizen Science can indeed make important contributions to sustainability transitions because it is uniquely able to address some central features of STs such as their socio-technical nature, large resource requirements, but also the important role of value judgments and politics. At the same time, CS faces important challenges that need to be addressed. We conclude by offering some critical reflections, highlighting opportunities for future

\footnotetext{
${ }^{19}$ Fritz et al. (2019) make a related effort by discussing more specifically how CS can help monitor sustainability goals.
} 
research, and considering implications for selected stakeholders.

\subsection{Critical reflections and future research}

Our discussion of opportunities and challenges focused on projects that involve both citizens and professional scientists; as such, we did not discuss explicitly the potential contributions of traditional academic science (which excludes citizens), but we also did not consider in depth the potential of autonomous or bottom-up CS (which excludes professional scientists). We chose this focus because in the context of sociotechnical transitions, we see the greatest opportunities and challenges precisely due to the collaboration between stakeholders with different capabilities, knowledge bases, and preferences. Indeed, we outlined in the beginning two extreme "views" of Citizen Science (featuring scientists and citizens as primary actors, respectively) and many of our core arguments emerged from the integration of these two views. That said, there may be distinct opportunities as well as challenges from autonomous CS that deserve future research.

In order to focus on the intersection between Citizen Science and sustainability transitions, we set aside several interesting issues raised in the literatures on which we draw. Among others, there are other important features of STs that we did not address, such as their multilevel nature, the presence of tipping points, or the role of a broader range of stakeholders (Loorbach et al., 2017; Rip, 1995). Similarly, we did not highlight other important issues in the study of Citizen Science such as project infrastructure (e.g., offline vs. online) or the role of context-dependent perceptions regarding the quality of scientific outcomes (Aceves-Bueno et al., 2017; Burgess et al., 2017). Although we do not believe that these other features change our key arguments, considering them in future work might yield a more nuanced and deeper understanding of the potential role of CS in STs.

Our discussion was driven by conceptual arguments relating core features of sustainability transitions to the two views of Citizen Science, but we also substantiated our arguments with empirical evidence drawn from prior research, case studies, our own CS experiences, and discussions with citizens and CS leaders. Some of this evidence is strong, including both large-scale quantitative studies and rich qualitative work on underlying mechanisms. Other evidence is only suggestive, and several of our arguments require empirical validation in future work. As such, we already pointed out several opportunities for future research throughout the paper. We now highlight three broader cross-cutting directions for future research on CS that seem particularly relevant in the context of sustainability transitions.

First, much of the prior literature focuses on the distinction between professional scientists and citizens. Future research is needed on the heterogeneity among citizens as well as among professional scientists: How do the objectives of citizens differ, and what political processes come into play as different groups seek to steer science towards their particular needs (Ribeiro et al., 2018)? How do different groups of citizens interact and collaborate within given projects, and how does diversity of participation relate to the quality of socio-technical solutions (Horwitz and Horwitz, 2007)? What are professional scientists' attitudes towards CS and STs, and which scientists select into using CS approaches? How can projects benefit from the leadership of professional scientists with different backgrounds, including the natural as well as the social sciences?

Second, the opportunities but also challenges for Citizen Science in sustainability transitions partly reflect that CS can be many things: Citizens can identify but also solve problems, they can provide effort as well as knowledge, and they can help address technical as well as social aspects of problems. An important question is whether these different aspects need to be realized within individual projects or whether they can be accomplished across a portfolio of different projects. While addressing aspects separately in different projects may help avoid some of the trade-offs and tensions we discussed (e.g., between scientific and educational goals), such a separation may also fail to address interdependencies between elements. As such, while most existing research focuses on the level of individual CS projects, future work should also consider the role of portfolios and how efforts might be coordinated across complementary projects. This will be especially important in the context of sustainability problems, which involve research needs that are large in both scale and scope. ${ }^{20}$

Third, future work should study the development of Citizen Science in light of advances in research tools and equipment. In particular, the capabilities of artificial intelligence (AI) and robotics are increasing rapidly, and many of the research tasks that used to require large amounts of human labor and intelligence can now be automated. This applies most clearly to work on digital objects such as classifying images, but also to data collection, problem solving, and even the identification of research questions (Fortson et al., 2012; Sparkes et al., 2010). ${ }^{21}$ As such, one may ask how much longer we will "need" Citizen Science. The answer partly depends on whether one sees the potential of CS narrowly in light of the "productivity view". We argued that the potential of Citizen Science in STs goes beyond increasing productivity, and it seems that new research technologies such as AI have limited potential to replace CS with respect to the three pathways discussed in Section 3. However, the increasing use of research technologies to increase efficiency may limit opportunities for citizens to engage in science and thus for non-scientific benefits to materialize. Thus, future work is needed on the interactions between CS and research technologies (as both enablers and substitutes), and how these interactions are shaped by project goals and overarching rationales for citizen participation in research.

\subsection{Implications for key actors}

The link between Citizen Science and sustainability transitions is not automatic. Instead, CS initiatives need to explicitly consider the nature of socio-technical transitions and leverage the pathways discussed in Section 3, while addressing the challenges raised in Section 4. We end by briefly noting implications for important actors such as citizens, professional scientists, administrators, as well as policy makers and funding agencies. ${ }^{22}$

First, citizens and professional scientists should reflect on their respective goals in CS projects and consider the benefits of integrating the "productivity" and "democratization" views. By discussing their goals and corresponding personal roles with each other, scientists and citizens may identify opportunities for their projects to have impacts beyond those originally intended. In a sense, this reinforces a point made earlier, namely that co-created projects have a particularly high potential to support sustainability transitions (Section 4.2.3). Of course, this also requires changes in norms and behaviors: Professional scientists need to share more control with citizens, consider non-scientific project goals, and explore the benefits of interdisciplinary approaches. At the same time, citizens need to accept additional responsibilities and may have to invest more time and effort than in typical contributory CS projects.

Academic administrators and peer evaluators need to recognize that the broader impact of CS cannot be fully captured in traditional performance metrics, and they should adjust reward systems to reduce the tensions discussed in Section 4.3.2. Administrators and educators can

\footnotetext{
${ }^{20}$ Emerging cross-project platforms such as EU-Citizen.Science seek to mainstream CS in science and policy and also provide an opportunity to foster and study interactions among projects.

${ }^{21}$ Of course, some tasks will not be automated in the foreseeable future. Moreover, artificial and human intelligence may also be complementary, e.g., when human-collected data are used to train algorithms or when algorithms increase the efficiency and quality of crowdsourcing (Keshavan et al., 2019).

${ }^{22}$ These implications assume that sustainability transitions tend to be beneficial and desirable. We recognize that this assumption may not be universally shared (see also Section 3.1 on the politics of STs).
} 
also foster CS for sustainability transitions by incorporating relevant aspects in the training and socialization of future generations of professional scientists. A more systematic educational approach may be needed given the significant changes that are required with respect to scientists' attitudes but also their skills and competences to engage in collaborations with citizens (O'Carroll et al., 2017). Such training could build upon - but needs to go beyond - current efforts related to science communication. $^{23}$

Policy makers and funding agencies should further encourage and support CS efforts, especially projects that are co-created to address sustainability problems. Supporting such projects is important because they are less likely to fit into the "productivity view" of academic institutions and may be less likely to emerge without external support. Moreover, such projects can be costlier to run, especially if they seek to reach a diverse range of citizens (see Section 4.1). Of course, policy makers and funding agencies need to be sensitive to the concerns and reservations on the part of professional scientists, while embracing their ability to shape and influence the academic system as important external stakeholders and resource providers.

Finally, we also see an important implication for our scholarly community. As discussed in Section 2, most of the current work on Citizen Science in fields such as the natural sciences, economics, or science and technology studies is rooted in one of the two views (productivity or democratization), emphasizing particular goals and mechanisms over others. Although such focused efforts yield important insights, they fail to appreciate the interdependencies between social and technical aspects and may result in recommendations that limit the potential of CS. As such, we call for greater interdisciplinary efforts that recognize and build upon different views to better understand Citizen Science and to provide guidance for practitioners and policy makers. Of course, the present article reflects our own limited attempt at such an integration.

\section{CRediT authorship contribution statement}

Henry Sauermann: Conceptualization, Writing - original draft, Writing - review \& editing. Katrin Vohland: Conceptualization, Writing - original draft, Writing - review \& editing, Funding acquisition. Vyron Antoniou: Conceptualization, Writing - original draft, Writing review \& editing. Bálint Balázs: Conceptualization, Writing - original draft, Writing - review \& editing. Claudia Göbel: Conceptualization, Writing - original draft, Writing - review \& editing, Funding acquisition. Kostas Karatzas: Conceptualization, Writing - original draft, Writing review \& editing. Peter Mooney: Conceptualization, Writing - original draft, Writing - review \& editing. Josep Perelló: Conceptualization, Writing - original draft, Writing - review \& editing. Marisa Ponti: Conceptualization, Writing - original draft, Writing - review \& editing, Funding acquisition. Roeland Samson: Conceptualization, Writing original draft, Writing - review \& editing. Silvia Winter: Conceptualization, Writing - original draft, Writing - review \& editing.

\section{Declaration of Competing Interest}

The authors declare that they have no known competing financial interests or personal relationships that could have appeared to influence the work reported in this paper.

\section{Acknowledgments}

This work benefited from the EU COST Action CA15212 "Citizen Science to promote creativity, scientific literacy, and innovation

\footnotetext{
${ }^{23}$ For example, the Lab for Open Innovation in Science (LOIS) conducts CS trainings as part of the $\mathrm{PhD}$ curriculum at the Berlin Einstein Center for Neurosciences (https://ois.lbg.ac.at/en/training/lois).
}

throughout Europe". BB received funding from the InSpires project, EU Horizon 2020 grant No 741677. JP was partially supported by MINEICO (Spain), Agencia Estatal de Investigación (AEI) and Fondo Europeo de Desarrollo Regional (FEDER) through grant FIS201678904-C3-2-P.

\section{References}

Aceves-Bueno, E., Adeleye, A.S., Feraud, M., Huang, Y., et al., 2017. The accuracy of citizen science data: a quantitative review. Bull. Ecol. Soc. Am. 98 (4), 278-290.

Ball, M.P., Bobe, J.R., Chou, M.F., Clegg, T., et al., 2014. Harvard personal genome project: lessons from participatory public research. Genome Med. 6 (2), 10.

Ballard, H.L., Dixon, C.G.H., Harris, E.M., 2017. Youth-focused citizen science: examining the role of environmental science learning and agency for conservation. Biol. Conserv. 20865-20875.

Beck, S., Brasseur, T.-.M., Poetz, M.K., Sauermann, H., 2019. What's the problem? Crowdsourcing research questions in science, Working Paper.

Bela, G., Peltola, T., Young, J., Balazs, B., et al., 2016. Learning and the transformative potential of citizen science. Conserv. Biol. 30 (5), 990-999.

Bercovitz, J., Feldman, M., 2008. Academic entrepreneurs: organizational change at the individual level. Org. Sci. 1969-1989.

Bio Innovation Service, 2018. Citizen science for environmental policy: development of an EU-wide inventory and analysis of selected practices.

Bonney, R., Cooper, C.B., Dickinson, J., Kelling, S., et al., 2009. Citizen science: a developing tool for expanding science knowledge and scientific literacy. Bioscience 59 (11), 977-984.

Bonney, R., Shirk, J.L., Phillips, T.B., Wiggins, A., et al., 2014. Next steps for citizen science. Science 343 (6178), 1436-1437.

Boon, W.P., Moors, E.H., Kuhlmann, S., Smits, R.E., 2011. Demand articulation in emerging technologies: intermediary user organisations as co-producers? Res. Policy 40 (2), 242-252.

Brossard, D., Lewenstein, B., Bonney, R., 2005. Scientific knowledge and attitude change: the impact of a citizen science project. Int J. Sci. Educ. 27 (9), 1099-1121.

Burgess, H., DeBey, L., Froehlich, H., Schmidt, N., et al., 2017. The science of citizen science: exploring barriers to use as a primary research tool. Biol. Conserv. 208113-208120.

Bush, V., 1945. Science - the Endless Frontier: A Report to the President on a Program for Postwar Scientific Research. National Science Foundation, Washington, D.C.

Callon, M., Rabeharisoa, V., 2008. The growing engagement of emergent concerned groups in political and economic life: lessons from the French association of neuromuscular disease patients. Sci. Technol. Human Values 33 (2), 230-261.

Christian, C., Lintott, C., Smith, A., Fortson, L., et al., 2012. Citizen science: contributions to astronomy research, in: Heck, A. (Ed.), Organizations, People and Strategies in Astronomy I. Venngeist, pp. 183-197.

Cigarini, A., Vicens, J., Duch, J., Sánchez, A., et al., 2018. Quantitative account of social interactions in a mental health care ecosystem: cooperation, trust and collective action. Sci. Rep. 8 (1), 3794.

Cohen, W.M., Sauermann H., Stephan P., Not in the job description: the commercial activities of academic scientists and engineers, Manag. Sci. forthcoming.

Collins, H.M., Pinch, T., 2012. The Golem: What You Should Know About Science. Cambridge University Press.

Couvet, D., Prevot, A.-.C., 2015. Citizen-science programs: towards transformative biodiversity governance. Envir. Develop. 13, 39-45.

Crain, R., Cooper, C., Dickinson, J.L., 2014. Citizen science: a tool for integrating studies of human and natural systems. Annu. Rev. Environ. Resour. 39, 641-665.

Crall, A.W., Jordan, R., Holfelder, K., Newman, G.J., et al., 2012. The impacts of an invasive species citizen science training program on participant attitudes, behavior, and science literacy. Public Understand. Sci. 22 (6), 745-764.

Cronje, R., Rohlinger, S., Crall, A., Newman, G., 2011. Does participation in citizen science improve scientific literacy? a study to compare assessment methods. Appl. Environ. Educ. Commun. 10 (3), 135-145.

Crowston, K., Fagnot, I., 2008. The motivational arc of massive virtual collaboration, Working Paper.

Davis, M., Laas, K., 2014. "Broader impacts" or "responsible research and innovation"? A comparison of two criteria for funding research in science and engineering. Sci. Eng. Ethics. 20 (4), 963-983.

Dickinson, J., Bonney, R., 2012. Citizen Science. Public Participation in Environmental Research. Compstock Publishing Associtates, pp. 1-279.

Dolgin, E., 2019. The hunt for the lesser-known funding source. Nature 570 (7759), 127.

Druschke, C.G., Seltzer, C.E., 2012. Failures of engagement: lessons learned from a citizen science pilot study. Appl. Environ. Edu. Commun. 11 (3-4), 178-188.

Edmondson, D.L., Kern, F., Rogge, K.S., 2019. The co-evolution of policy mixes and sociotechnical systems: towards a conceptual framework of policy mix feedback in sustainability transitions. Res. Policy. 48 (10), 103555.

English, P., Richardson, M., Garzón-Galvis, C., 2018. From crowdsourcing to extreme citizen science: participatory research for environmental health. Annu. Rev. Public Health 39335-39350.

European Citizen Science Association, 2015. ECSA strategy.

European Commission, 2017. Horizon 2020. Work Programme 2018-2020., pp. 1-74.

European Science Foundation, 2013. Science In Society: Caring For Our Futures In Turbulent Times. European Science Foundation.

Eveleigh, A., Lynn, S., Cox, A., Jennett, C., 2013. I want to be a captain! gamification in the old weather citizen science project. Gamification '13: First International 
Conference on Gameful Design, Research, and Applications.

ExCiteS, 2019. Citizen science and botanic knowledge among herders and farmers in Kenya.

Fagerberg, J., 2018. Mobilizing innovation for sustainability transitions: a comment on transformative innovation policy. Res. Policy 47 (9), 1568-1576.

Felt, U., Fochler, M., 2008. The bottom-up meanings of the concept of public participation in science and technology. Sci. Public Policy 35 (7), 489-499.

Follett, R., Strezov, V., 2015. An analysis of citizen science based research: usage and publication patterns. PLoS ONE 10 (11), e0143687.

Fortson, L., Masters, K., Nichol, R., Borne, K., et al., 2012. Galaxy Zoo: morphological classification and citizen science. . Advances in Machine Learning and Data Mining For Astronomy. CRC Press, Taylor \& Francis Group, pp. 1-11.

Franzoni, C., Sauermann, H., 2014. Crowd science: the organization of scientific research in open collaborative projects. Res. Policy 43 (1), 1-20.

Fritz, S., See, L., Carlson, T., Haklay, M.M., et al., 2019. Citizen science and the United Nations sustainable development goals. Nature Sustain. 2 (10), 922-930.

Ganzevoort, W., Born, R.J.G.v.d., Halffman, W., Turnhout, S., 2017. Sharing biodiversity data: citizen scientists' concerns and motivations. Biodivers ConservDOI10.1007/ s10531-10017-11391-z.

Geels, F.W., 2002. Technological transitions as evolutionary reconfiguration processes: a multi-level perspective and a case-study. Res. Policy 31 (8-9), 1257-1274.

Geels, F.W., 2006. The hygienic transition from cesspools to sewer systems (1840-1930): the dynamics of regime transformation. Res. Policy 35 (7), 1069-1082.

Geels, F.W., Schot, J., 2007. Typology of sociotechnical transition pathways. Res. Policy 36 (3), 399-417.

Geoghegan, H., Dyke, A., Pateman, R., West, S., et al., 2016. Understanding Motivations for Citizen Science. UK Environmental Observation Framework.

Gieryn, T.F., 1983. Boundary-work and the demarcation of science from non-science: strains and interests in professional ideologies of scientists. American Sociological Review781-795.

Golumbic, Y.N., Orr, D., Baram-Tsabari, A., Fishbain, B., 2017. Between vision and reality: a study of scientists' views on citizen science. Citizen Science: Theory and Practice 2 (1), 1-13.

Groom, Q., Weatherdon, L., Geijzendorffer, I.R., 2017. Is citizen science an open science in the case of biodiversity observations? J. Appl. Ecol. 54 (2), 612-617.

Groulx, M., Brisbois, M.C., Lemieux, C.J., Winegardner, A., et al., 2017. A role for naturebased citizen science in promoting individual and collective climate change action? a systematic review of learning outcomes. Sci. Commun. 39 (1), 45-76.

Grundmann, R., 2013. "Climategate" and the scientific ethos. Sci. Technol. Human Values 38 (1), 67-93.

Hackett, E.J., 1990. Science as a vocation in the 1990s. J. Higher Edu. 61 (3), 241-279.

Hackman, J.R., Oldham, G.R., 1976. Motivation through the design of work - Test of a theory. Organ Behav. Hum. Perform 16 (2), 250.

Haklay, M., 2015. In: Scholars, W.W.I.C.f. (Ed.), Washington DC

Hallmann, C.A., Sorg, M., Jongejans, E., Siepel, H., et al., 2017. More than 75 percent decline over 27 years in total flying insect biomass in protected areas. PLoS ONE 12 (10), e0185809.

Head, B.W., 2008. Wicked problems in public policy. Public Policy 3 (2), 101-118.

Hecker, S., Garbe, L., Bonn, A., 2018. The European citizen science landscape - a snapshot. In: Hecker, S., Haklay, M., Bowser, A., Makuch, Z., Vogel, J., Bonn, A. (Eds.), Citizen science: Innovation in Open science, Society and Policy. UCL Press, London, pp. 190-200.

Heiss, R., Matthes, J., 2017. Citizen science in the social sciences: a call for more evidence. GAIA-Ecol. Perspect. Sci. Soc. 26 (1), 22-26.

Hekkert, M.P., Suurs, R.A., Negro, S.O., Kuhlmann, S., et al., 2007. Functions of innovation systems: a new approach for analysing technological change. Technol. Forecast. Soc. Change 74 (4), 413-432.

Hielscher, S., Jaeger-Erben, M., 2019. Resisting obsolescence? the role of a "culture of repair" for product longevity. In: Nissen, N., M., J.-E. (Eds.), PLATE Product Lifetimes and The Environment. TU Berlin University Press, Berlin.

Hölscher, K., Wittmayer, J.M., Loorbach, D., 2018. Transition versus transformation: what's the difference?Environmental Innovation and Societal Transitions271-273.

Horwitz, S.K., Horwitz, I.B., 2007. The effects of team diversity on team outcomes: a meta-analytic review of team demography. J. Manage 33 (6), 987-1015.

Hyder, K., Wright, S., Kirby, M., Brant, J., 2017. The role of citizen science in monitoring small-scale pollution events. Marine Pollut. Bull. 120 (1-2), 51-57.

Innocentive, 2007. InnoCentive solver develops solution to help clean up remaining oil from the 1989 Exxon Valdez disaster.

Irwin, A., 1995. Citizen science: a study of people. expertise and sustainable development. Routledge, London and New York.

Irwin, A., 2014. From deficit to democracy (re-visited). Public Understand. Sci. 23 (1), $71-76$.

Jackson, C., Østerlund, C., Maidel, V., Crowston, K., et al., 2016. Which way did they go? Newcomer movement through the Zooniverse. Proceedings of the 19th ACM Conference on Computer-Supported Cooperative Work \& Social Computing. ACM, pp. 624-635.

Jasanoff, S., 2003. Technologies of humility: citizen participation in governing science. Minerva 41 (3), 223-244.

Jeppesen, L.B., Lakhani, K.R., 2010. Marginality and problem-solving effectiveness in broadcast search organization science 21 (5), 1016-1033.

Jordan, R.C., Gray, S.A., Howe, D.V., Brooks, W.R., et al., 2011. Knowledge gain and behavioral change in citizen-science programs. Conserv. Biol. 25 (6), 1148-1154.

Jørgensen, U., 2012. Mapping and navigating transitions-The multi-level perspective compared with arenas of development. Res Policy 41 (6), 996-1010.

Jury, W.A., Vaux, H., 2005. The role of science in solving the world's emerging water problems. Proc. Natl. Acad. Sci. U.S.A. 102 (44), 15715-15720.
Keshavan, A., Yeatman, J.D., Rokem, A., 2019. Combining citizen science and deep learning to amplify expertise in neuroimaging. Frontiers in Neuroinformatics 1329.

Khatib, F., DiMaio, F., Foldit Contenders Group, Foldit Void Crushers Group, 2011. Crystal structure of a monomeric retroviral protease solved by protein folding game players. Nat. Struct. Mol. Biol. 18 (10), 1175-1177.

Kline, S.J., Rosenberg, N., 2010. Innovation and the chain-linked model. Studies On Science And The Innovation Process: Selected Works of Nathan Rosenberg. World Scientific, pp. 173-203.

Kolb, A.Y., Kolb, D.A., 2005. Learning styles and learning spaces: enhancing experiential learning in higher education. Acad. Manag. Learn. Edu. 4 (2), 193-212.

Krainer, L., Winiwarter, V., 2016. Universities as actors in transformative science. Consequences for assessing transdisciplinary research quality. Gaia 25 (2), 110-116.

Kuhlmann, S., Rip, A., 2018. Next-generation innovation policy and grand challenges. Sci. Public Policy 45 (4), 448-454.

Kullenberg, C., Kasperowski, D., 2016. What is citizen science? - A scientometric metaanalysis. PLoS ONE 11 (1), e0147152.

Kythreotis, A.P., Mantyka-Pringle, C., Mercer, T.G., Whitmarsh, L.E., et al., 2019. Citizen social science for more integrative and effective climate action: a science-policy perspective. Frontiers in Environmental Science710.

Latour, B., 1987. Science In Action: How to Follow Scientists and Engineers Through Society. Harvard Univ Press.

Lewandowsky, S., Mann, M.E., Brown, N.J., Friedman, H., 2016. Science and the public: debate, denial, and skepticism. J. Soc. Polit. Psychol. 4 (2), 537-553.

Loorbach, D., Frantzeskaki, N., Avelino, F., 2017. Sustainability transitions research: transforming science and practice for societal change. Annu. Rev. Environ. Resour. $42599-42626$.

Ludwig Boltzmann Gesellschaft, 2018. Crowdsourcing research questions in science.

Mahr, D., 2014. Citizen Science: partizipative Wissenschaft im späten 19. und frühen 20. Jahrhundert. . Nomos. see https://pub.uni-bielefeld.de/record/2684966.

Markard, J., Raven, R., Truffer, B., 2012. Sustainability transitions: an emerging field of research and its prospects. Res. Policy 41 (6), 955-967.

May, A.M., McGarvey, M.G., Whaples, R., 2014. Are disagreements among male and female economists marginal at best? A survey of AEA members and their views on economics and economic policy. Contemp. Econ. Policy 32 (1), 111-132.

McCormick, S., 2007. Democratizing science movements: a new framework for mobilization and contestation. Soc. Stud. Sci. 37 (4), 609-623.

McGrane, 2017. The German amateurs who discovered "Insect armageddon", The New York Times.

Merton, R.K., 1973. The Sociology of Science: Theoretical and Empirical Investigations. University of Chicago Press, Chicago.

Miller-Rushing, A., Primack, R., Bonney, R., 2012. The history of public participation in ecological research. Front. Ecol. Environ. 10 (6), 285-290.

Mowery, D.C., Nelson, R.R., Martin, B.R., 2010. Technology policy and global warming: why new policy models are needed (or why putting new wine in old bottles won't work). Res. Policy 39 (8), 1011-1023.

Mueller, M., Tippins, D., Bryan, L., 2012. The future of citizen science. Democ. Edu. 20 (1) 1 -

Nelson, R., 2004. The market economy, and the scientific commons. Res. Policy 33 (3), 455-471.

Newman, G., Wiggins, A., Crall, A., Graham, E., et al., 2012. The future of citizen science: emerging technologies and shifting paradigms. Front. Ecol. Environ. 10 (6), 298-304.

Nielsen, M., 2011. Reinventing Discovery: The New Era of Networked Science. Princeton University Press.

Nowotny, H., 2003. Democratising expertise and socially robust knowledge. Science and Public Policy 30 (3), 151-156.

O'Carroll, C., Kamerlin, C., Brennan, N., Hyllseth, B., et al., 2017. Providing researchers with the skills and competencies they need to practise open science. In: W.G.o.E.a.S.u.O (Ed.), Science. Publications Office of the European Union.

Ottinger, G., 2010. Buckets of resistance: standards and the effectiveness of citizen science. Sci. Technol. Human Values 35 (2), 244-270.

Parrish, J.K., Jones, T., Burgess, H.K., He, Y., et al., 2019. Hoping for optimality or designing for inclusion: persistence, learning, and the social network of citizen science. Proc. Natl. Acad. Sci. 116 (6), 1894-1901.

Patterson, J., Schulz, K., Vervoort, J., Van Der Hel, S., et al., 2017. Exploring the governance and politics of transformations towards sustainability. Environ. Innov. Soc. Trans. 24, 1-16.

Perkmann, M., Tartari, V., McKelvey, M., Autio, E., et al., 2013. Academic engagement and commercialisation: a review of the literature on university-industry relations. Res. Policy 42 (2), 423-442.

Petridis, P., Fischer-Kowalski, M., Singh, S.J., Noll, D., 2017. The role of science in sustainability transitions: citizen science, transformative research, and experiences from Samothraki island. Greece. Island Stud. J. 12 (1), 115-134.

Pettibone, L., Blättel-Mink, B., Balázs, B., Giulio, A.D., et al., 2018. Transdisciplinary sustainability research and citizen science: options for mutual learning. Gaia 27 (2), 222-225.

Poetz, M.K., Schreier, M., 2012. The value of crowdsourcing: can users really compete with professionals in generating new product ideas? J. Prod. Innov. Manag. 29 (2), 245-256.

Potts, S.G., Ngo, H.T., Biesmeijer, J.C., Breeze, T.D., et al., 2016. The assessment report of the intergovernmental science-policy platform on biodiversity and ecosystem services on pollinators, pollination and food production.

Pradhan, P., Costa, L., Rybski, D., Lucht, W., et al., 2017. A systematic study of sustainable development goal (SDG) interactions. Earth's Future 5 (11), 1169-1179.

Raddick, M.J., Bracey, G., Gay, P.L., Lintott, C., et al., 2013. Galaxy zoo: motivations of citizen scientists. Astron. Educ. Rev. 12 (1).

Ribeiro, B., Bengtsson, L., Benneworth, P., Bührer, S., et al., 2018. Introducing the 
dilemma of societal alignment for inclusive and responsible research and innovation. J. Respons. Innov. 5 (3), 316-331.

Riesch, H., Potter, C., 2014. Citizen science as seen by scientists: methodological, epistemological and ethical dimensions. Public Understand. Sci. 23 (1), 107-120.

Rip, A., 1995. Introduction of new technology: making use of recent insights from sociology and economics of technology. Technol. Anal. Strat. Manag. 7 (4), 417-432.

Rittel, H.W., Webber, M.M., 1973. Dilemmas in a general theory of planning. Policy Sci. 4 (2), 155-169.

Ruckart, P.Z., Ettinger, A.S., Hanna-Attisha, M., Jones, N., et al., 2019. The flint water crisis: a coordinated public health emergency response and recovery initiative. J. Public Health Manag. Pract.25S84.

Ruiz-Mallén, I., Riboli-Sasco, L., Ribrault, C., Heras, M., et al., 2016. Citizen science: toward transformative learning. Sci. Commun. 38 (4), 523-534.

Sauermann, H., Franzoni, C., 2013. Participation dynamics in crowd-based knowledge production: the scope and sustainability of interest-based motivation, SSRN Working Paper.

Sauermann, H., Franzoni, C., 2015. Crowd science user contribution patterns and their implications. Proc. Natl. Acad. Sci. 112 (3), 679-684.

Sauermann, H., Roach, M., 2014. Not all scientists pay to be scientists: PhDs' preferences for publishing in industrial employment. Res. Policy 43 (1), 32-47.

Sauermann, H., Shafi, K., Franzoni, C., 2019. Crowdfunding scientific research: descriptive insights and correlates of funding success. PLOS ONE.

Sauermann, H., Stephan, P., 2013. Conflicting logics? A multidimensional view of industrial and academic science. Org. Sci. 24 (3), 889-909.

Science Europe, 2018. Science Europe briefing paper on citizen science.

Senabre, E., Ferran-Ferrer, N., Perelló, J., 2018. Participatory design of citizen science experiments. Revista Comunicar 54 (26), 29-38.

Shapin, S., 2008. The Scientific Life: A Moral History of a Late Modern Vocation. University of Chicago Press.

Shirk, J.L., Ballard, H.L., Wilderman, C.C., Phillips, T., et al., 2012. Public participation in scientific research: a framework for deliberate design. Ecol. Soc. 17 (2), 29.

Simis, M.J., Madden, H., Cacciatore, M.A., Yeo, S.K., 2016. The lure of rationality: why does the deficit model persist in science communication? Public Understand. Sci. 25 (4), 400-414.

Simonton, D.K., 2003. Scientific creativity as constrained stochastic behavior: the integration of product, person, and process perspectives. Psychol. Bull. 129 (4), 475-494.

Siva, N., 2014. Crowdfunding for medical research picks up pace. Lancet North Am. Ed. 384 (9948), 1085-1086.

Smith, A., Stirling, A., Berkhout, F., 2005. The governance of sustainable socio-technical transitions. Res. Policy 34 (10), 1491-1510.

Smith, A., Voß, J.-.P., Grin, J., 2010. Innovation studies and sustainability transitions: the allure of the multi-level perspective and its challenges. Res. Policy 39 (4), 435-448.

Sparkes, A., Aubrey, W., Byrne, E., Clare, A., et al., 2010. Towards robot scientists for autonomous scientific discovery. Autom. Exp. 2 (1), 1.

Stilgoe, J., 2009. Citizen Scientists: Reconnecting Science with Civil Society. Demos, London.

Stilgoe, J., Lock, S.J., Wilsdon, J., 2014. Why should we promote public engagement with science? Public Understand. Sci. 23 (1), 4-15.
Stilgoe, J., Owen, R., Macnaghten, P., 2013. Developing a framework for responsible innovation. Res. Policy 42 (9), 1568-1580.

Stokes, D., 1997. Pasteur's Quadrant: Basic Science and Technological Innovation. Brookings Institution Press, Washington, DC.

Strasser, B.J., 2012. Collecting nature: practices, styles, and narratives. Osiris 27, 303-340.

Sullivan, B.L., Wood, C.L., Iliff, M.J., Bonney, R.E., et al., 2009. eBird: a citizen-based bird observation network in the biological sciences. Biol. Conserv. 142 (10), 2282-2292.

SwafS, 2017. Citizen science policies in the European Commission. Science with and for Society Policy Brief.

Toomey, A.H., Domroese, M.C., 2013. Can citizen science lead to positive conservation attitudes and behaviors? Human Ecol. Rev. 20 (1), 50-62.

Trisos, C.H., Alexander, S.M., Gephart, J.A., Gurung, R., et al., 2019. Mosquito net fishing exemplifies conflict among sustainable development goals. Nature Sustain. 2 (1), 5.

Turrini, T., Dörler, D., Richter, A., Heigl, F., et al., 2018. The threefold potential of environmental citizen science-Generating knowledge, creating learning opportunities and enabling civic participation. Biol. Conserv. 225176-225186.

U.S. Federal Citizen Science Initiative, 2018

United Nations, 1987. Report of the world commission on environment and development: our common future.

Van Brussel, S., Huyse, H., 2018. Citizen science on speed? Realising the triple objective of scientific rigour, policy influence and deep citizen engagement in a large-scale citizen science project on ambient air quality in Antwerp. J. Environ. Plann. Manage. $1-18$.

Van de Poel, I., 2003. The transformation of technological regimes. Res. Policy 32 (1), 49-68.

Van der Brugge, R., Rotmans, J., Loorbach, D., 2005. The transition in Dutch water management. Reg. Environ. Change 5 (4), 164-176.

Vohland, K., Göbel, C., 2017. Open science und citizen science als symbiotische beziehung? TATuP Zeitschrift für Technikfolgenabschätzung in Theorie und Praxis 26 (1-2), 18-24.

Von Hippel, E., 1994. Sticky information and the locus of problem solving: implications for innovation. Manage Sci 40 (4), 429-439.

Von Schomberg, R., 2013. Chapter 3: A vision of responsible research and innovation. In: Owen, R., Bessant, J., Heintz, M. (Eds.), Responsible innovation, pp. 51-74.

Weber, M., 1997. The methodology of social sciences. Free Press, New York.

West, S., Pateman, R., 2016. Recruiting and retaining participants in citizen science: what can be learned from the volunteering literature? Citizen Science: Theory and Practice 1 (2), 1-10. see http://eprints.whiterose.ac.uk/114091/1/Recruiting_and_retaining_ volunteers.pdf.

West, S., Pateman, R., 2017. How Could Citizen Science Support the Sustainable Development Goals? Stockholm Environment Institute.

Wiggins, A., Crowston, K., 2011. From conservation to crowdsourcing: a typology of citizen science. In: 44th Hawaii International Conference on Systems Sciences (HICSS) IEEE, pp. 1-10.

Woolley, J.P., McGowan, M.L., Teare, H.J., Coathup, V., et al., 2016. Citizen science or scientific citizenship? Disentangling the uses of public engagement rhetoric in national research initiatives. BMC Med. Ethics 17 (1), 33. 